“Are you human beings?" Order and knowledge construction through questioning in primary classroom interaction

$\underline{\text { Abstract }}$ This article examines how question-answer sequences are constructed in primary school instructional activities. The interaction between teacher and students in two $3^{\text {rd }}$-year groups is analyzed using a conversation-analytic approach. Four questioning patterns - yes-no, alternative, wh-questions, and a non-interrogative format very frequently used in this setting which I call the Eliciting Completion Device (ECD)- teachers use to address the class as a whole are examined in relation to their sequential uptakes: in-unison answers and bids to answer. The analysis shows that students recognize the conventions of question construction as methodical practices used by teachers to convey expectations as to whether the answer is accessible to students. Choral responses are produced when the question is constructed as eliciting information which is obviously known to students, while bids to answer are deployed when the answer is less transparent. The findings reveal that the practices used to construct collectively assembled knowledge are closely connected to the organization of the classroom social order.

\title{
"ARE YOU HUMAN BEINGS?" : ORDER AND KNOWLEDGE CONSTRUCTION THROUGH QUESTIONING IN PRIMARY CLASSROOM INTERACTION
}

\section{Introduction}

Imparting knowledge to a new generation of learners in an institutional setting is primarily an interactional activity, though the way in which participants construct and manage interaction is a matter not to be taken for granted. As studies on cultural variations in teaching and ethnographic research on educational practices have shown, in many societies instructional activities are implemented through 
different ways of organizing interaction (Philips, 1972 and 1983; Schultz, Florio and Erickson, 1982;

Heath, S.B. 1983; Ochs, 1982; Ochs and Schieffelin, 1983; Cazden, 1986; Rogoff, 1990; Mercer, 1995). For instance, in many communities adults guide the construction of knowledge primarily through providing opportunities for observation and imitation of instructors/elders, while in other cultures, as in our Western societies, talking to pupils, and furthermore asking questions, seem to be the main instructional practices employed in institutional education settings.

It goes without saying that classroom interaction involves a number of activities through which teaching and learning tasks can be accomplished without asking questions, and some require no talking at all. For instance, teachers and students tell stories to each other, read poetry, stories or tales, solve problems, and write essays. All of these pedagogic endeavors involve, at a certain stage, particular oral activities: the statement of ideas and concepts, the organization of knowledge, the development of abilities and competences. Questions and answers are the most prevalent instructional tools in a long standing pedagogic tradition in which the centrality of questions in teaching is widely recognized (Sinclair and Coulthard, 1975; Mehan, 1979; Cazden, 1986; French and McLure, 1981; Wilkinson, 1982; McHoul, 1978; Levinson, 1992; Mercer, 1995; Galton et al., 1999; Nassaji and Wells, 2000; Nystrand et al., 2003) and which is claimed, by some, to have come down all the way from Socrates.

One of the main institutional aims that teachers and students achieve through interaction is that of imparting and gaining new knowledge. This often involves, as a first step, a collective assembling of known information. Indeed, teachers use a range of questioning devices to elicit from students notions they already possess: that is, they prompt displays of knowledge. These notions then serve as the foundation upon which new information and competences are built. For this purpose, teachers have a wide range of interactional resources and practices at their disposal. For example, by leaving the last word in a sentence to be completed by the students, a teacher clearly relies on previous knowledge possessed by the students and invites their collaborative completion, as shown in fragment 1 below: 
(1) Neolithic [PM:LL:1a.history/prehistory

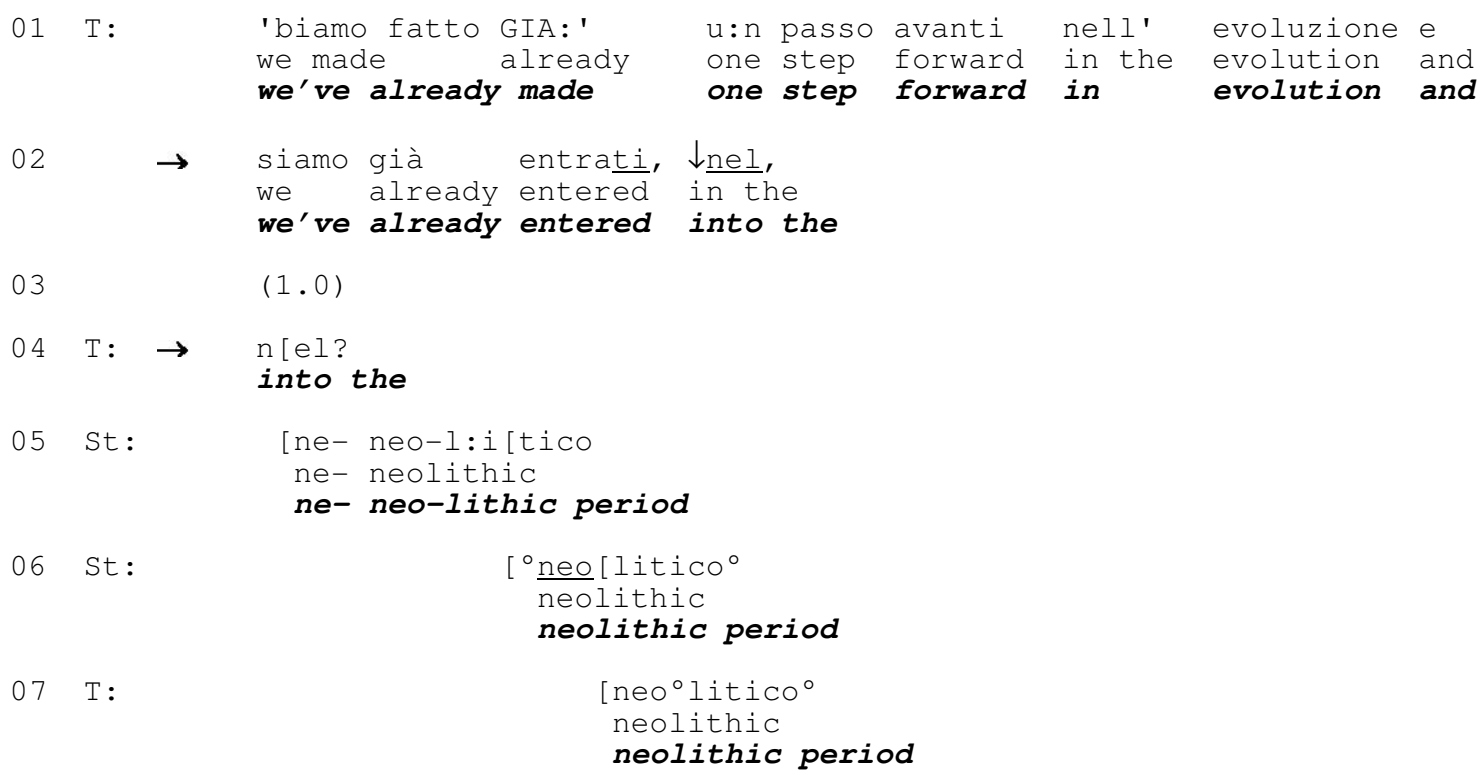

By withholding the production of the last word, highlighted also by a substantial period of silence in line 3, the teacher invites the students to display their knowledge of the unspoken item by supplying it in the empty slot.

Teachers draw on a variety of resources in designing questioning. Their goal in each case is to elicit a certain type of answer, given by students in a certain manner and located in a particular place in the interaction. In the excerpt above, for example, before the witholding of the turn's last item and the one-second gap in line 3, the teacher produces a cluster of prosodic features, including rising intonation, emphasis, and pitch variations. In this way, the teacher provides students with the opportunity to understand what is left unspoken and thus, to display their knowledge and demonstrate that they are so attuned to the talk underway that they can complete the teacher's unfinished turn. This practice, which I analyze in this paper and call the Eliciting Completion Device (ECD), is only one of the methods employed by teachers when designing questioning turns ${ }^{\mathrm{i}}$.

Classrooms are multi-party settings. Teachers face a large audience and must be capable of controlling and organizing students' participation so that pedagogical activities are accessible to all. 
Therefore, the construction of shared knowledge interlocks with the organization of the classroom social order (Mehan, 1979; McHoul, 1978). Through patterns of questioning the teacher controls the students' verbal and non-verbal participation, determining who speaks, when and how. At times the teacher aims to elicit a collective response from the whole class, while on other occasions the question is constructed to address only one particular student. In other words, the way in which a question gets shaped has important consequences for the social order of the classroom, in terms of how the teacher keeps the students focused on the activities and controls the order and format of speaking turns. Thus, it emerges that the activity of building knowledge has indissoluble ties with that of keeping and maintaining order in the classroom.

The focus in this article is on questions that are not addressed to a single student (pre-allocated). The main interest is on how differences in the construction of this type of questions relate to the format of the answers: either choral and individual responses. Through the investigation of the ways in which teachers construct questioning turns and the shape of their sequential uptakes, this paper aims to explicate the relationship between the construction of shared knowledge and the maintainance of the social order in the classroom. Before exploring the details of these questioning formats and their outcomes, some preliminary considerations on the categorization of addressed and non-addressed questions are necessary.

\subsection{Addressed and non-addressed questions and their outcomes}

One immediately visible feature of the construction of questions, which has consequences for the way in which teacher/student interaction is organized, is the presence or absence in the questioning 
turn of addressing terms. Naming one student when constructing a question is one way to deal with the problem of selecting who shall answer, as in fragment 2 below:

(2) Natural and artificial [PM:FZ:12a: geography]

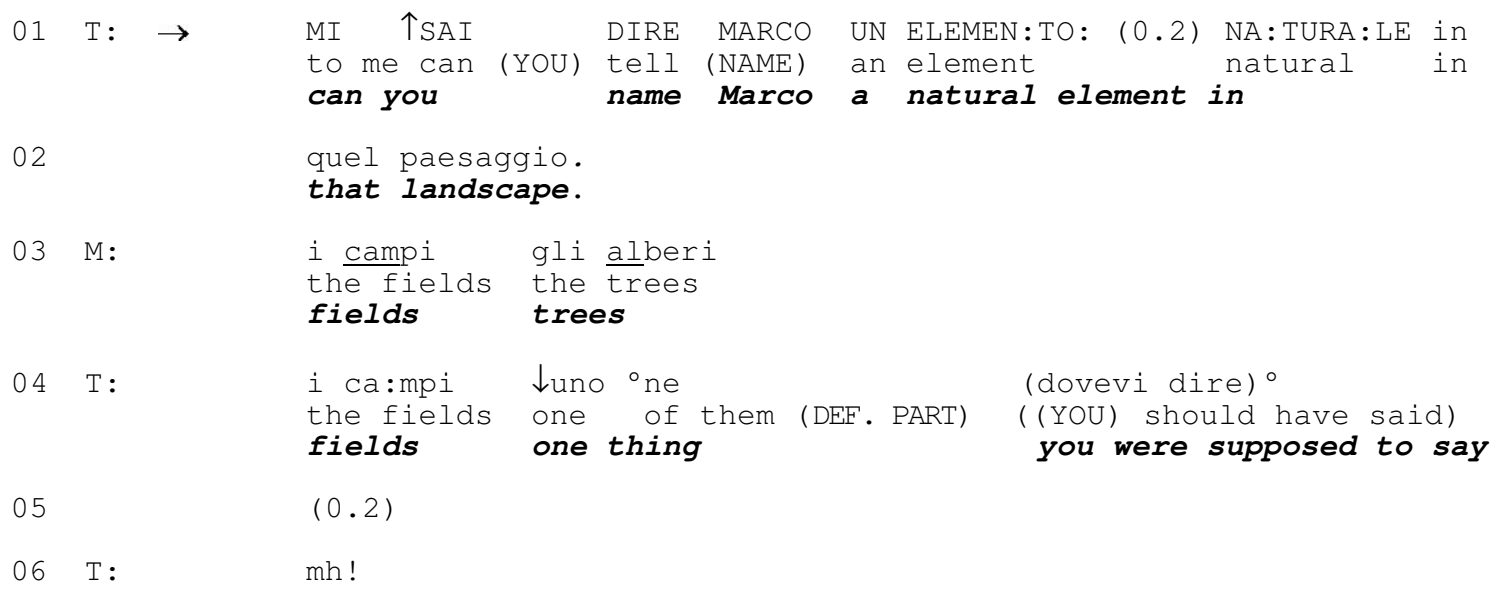

The student named in line 1 answers directly in line 3 . The teacher then assesses the answer in the following line.

However, things are not always so neat and clear. For instance, the question in line 3 in the fragment below, although clearly addressed to Janin, produces a choral uptake.

(3) Boxes [PM:FZ:21:maths]

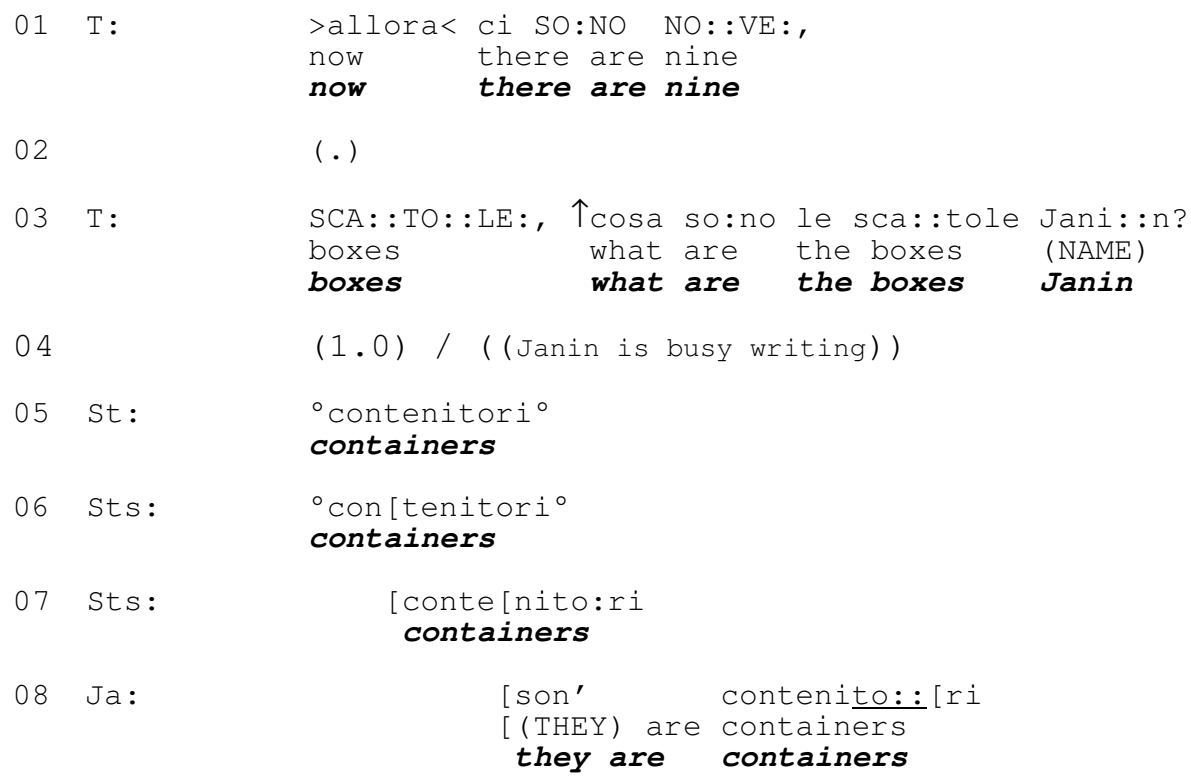


As shown in the transcript, here the selected student does not answer immediately. Possible reasons for the delay can be the following: (i) Janin is busy writing when the teacher addresses the question to her; (ii) the question follows a session of talk in which students have been allowed to give their individual answers without any selection procedure or pre-allocation; and Janin might be still orienting to this type of organization. This delay, however, provides opportunities for the other pupils to supply the answer before Janin finally comes in (line 8). The example shows a case in which the question is addressed to a single student, but that is not how it is answered, owing to the local management of the activities underway.

By contrast, the question in Fragment 4 below is left un-addressed. The teacher does not name any student in particular, and the nonverbal behavior which accompanies the delivery of the questioning (see the gloss to lines 1 and 5) also seems to suggest that all the students are proposed here as potential addressees of the question. Despite this, individual students present themselves as potential answerers ${ }^{1}$.

\section{(4) Medical substances [PM:FZ:12b:geography ]}

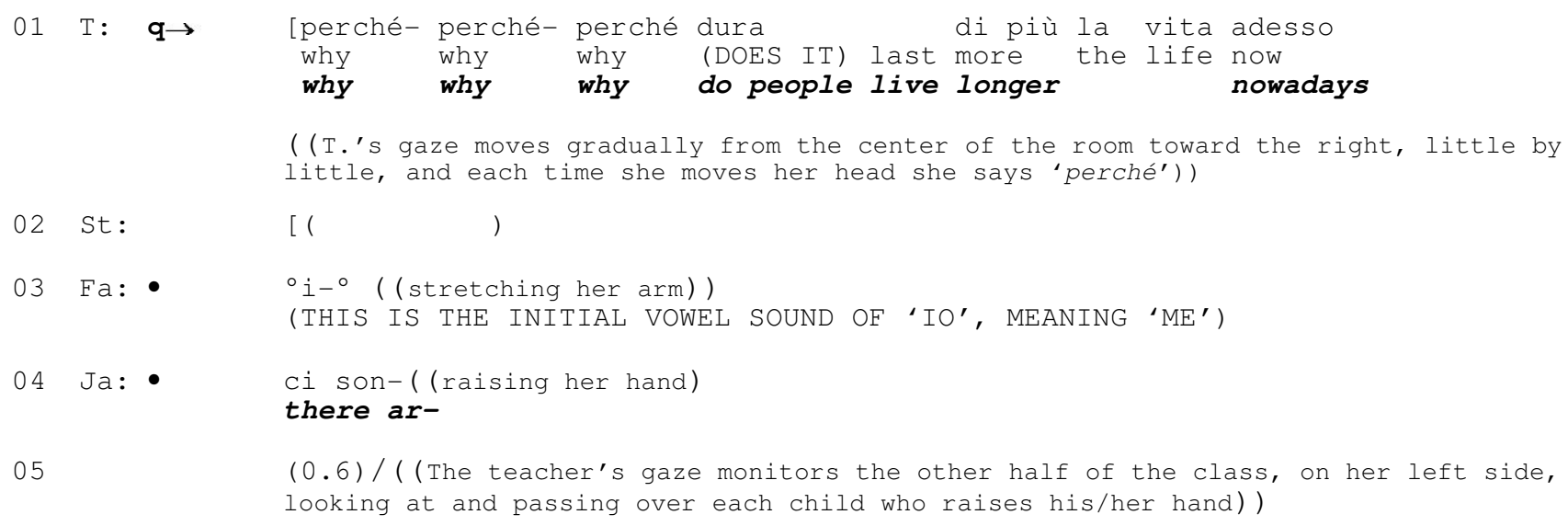

\footnotetext{
${ }^{1}$ The lines in which students propose themselves as potential next speakers are indicated in the transcript with this symbol $(\bullet)$, in lines 3, 4, and 6 .
} 


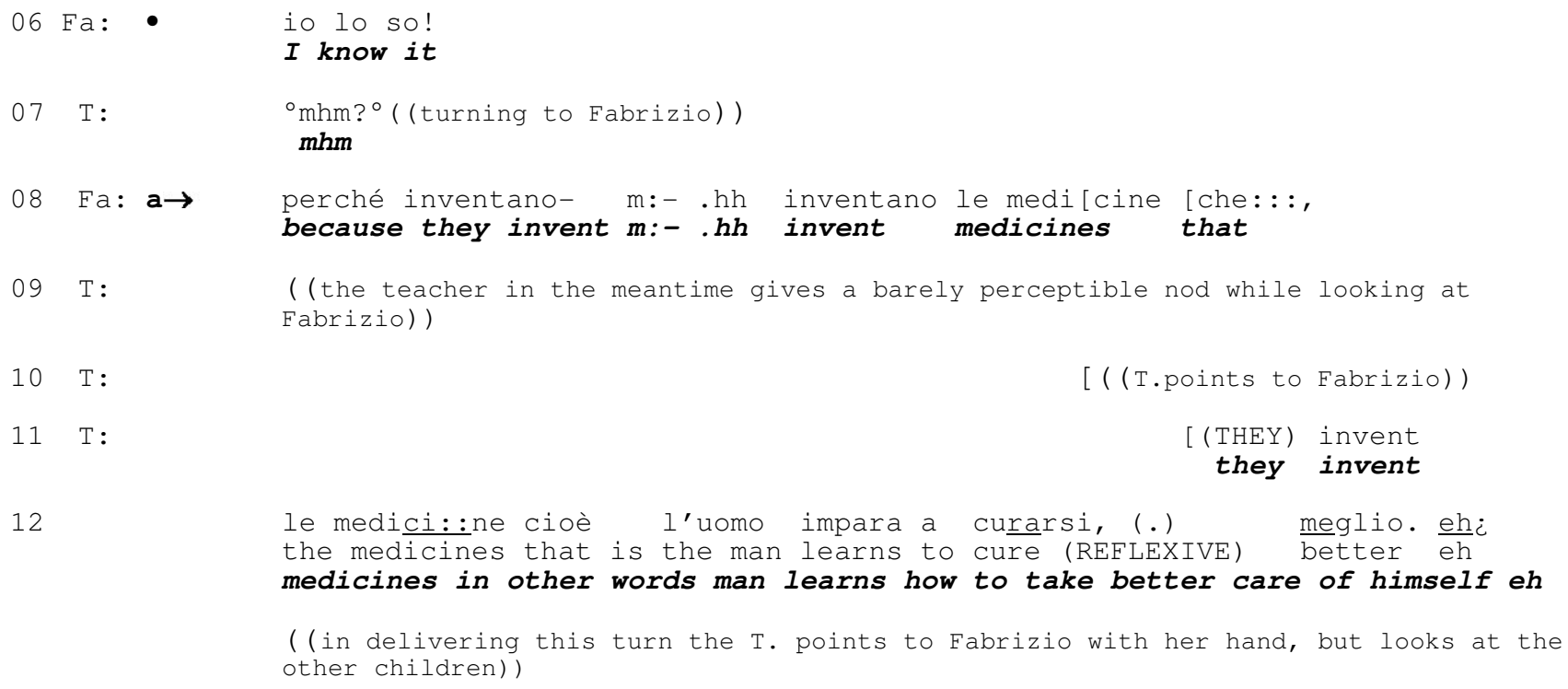

Here the audience organizes the answering sequence following a precise procedure. Before a specific student is selected and gives the answer (line 8), a number of students produce either verbal or gestural bids to answer (indicated by the graphic symbol •), initiating an inserted sequence in which the teacher is expected to make a selection, which is accomplished in line 7.

However, answers to questions that are non-addressed are not always preceded by bids. For instance, the question in the fragment below engenders a different organization in the production of answers: students provide choral answers after a single respondent anticipates the others in line 2 .

\section{(5) Angles (PM:LT:5a.geometry)}

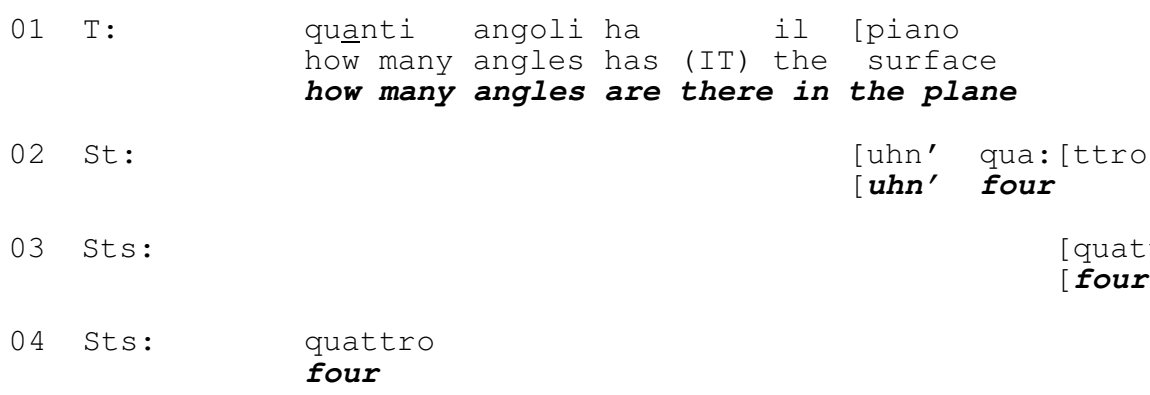

In fragment 6 below, the answer is again produced right away and in unison, following a non-addressed question.

(6) Boxes II [PM:FZ:21.maths]

01 T: DEVO TROVARE IL NUMERO DELLE SCA::TOLEi




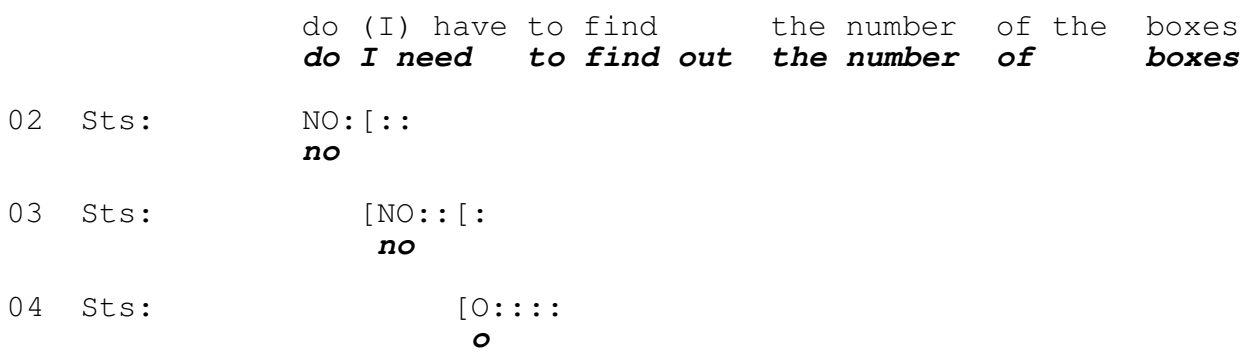

In both fragments the answer is provided without any selection procedure. In both fragments, but more neatly in fragment 6 , the students organize themselves in responding groups which perfectly time their production, giving choral answers.

As the examples above clearly show, the characterization of addressed and non-addressed questions is rather broad and glosses over some crucial features in the question construction and in the interactional context (such as, for instance, the delay of the selected student in producing the answer, as we have seen in example 3) and perhaps oversimplifies sequential consequences such as who is expected or entitled to answer and in which way this is to be done. Apparently, as emerges from the above examples, there is no direct relationship between addressed question and individually produced answer nor between non-addressed question and collectively produced answer. Furthermore, as fragments 4,5 and 6 show, non-addressed questions seem to engender two main types of answering patterns: choral answers and bids to answer (either verbal or non-verbal, such as hand-raising).

The fact that two different outcomes are possible after non-addressed questions is significant in terms of the orderly progression of interaction. Students seem to recognize indications which lie in the features of question construction, and which do not always coincide with the teacher's explicit naming of the selected student, when interpreting the specific requirements of the question. It seems, in fact, that the rules participants follow in order to manage the unfolding of interaction in classroom instructional sequences, and particularly those which students adhere to in order to produce the 'expected' answer, are conveyed by the very construction of the question. 
The analysis that follows focuses on questions which are not addressed to a specific student, and which yield either choral answers or individual bids to answer. From the way in which non-addressed questions are designed, students interpret whether individual or collective answers are expected.

In particular, with reference to choral answers, we will find that the prior questioning turns which elicit them embody a sense of obviousness that ends up being conveyed in the answer as well. Teachers use a variety of prosodic and syntactic formats and, more generally, features in the construction and deployment of questions (1) to display their assumptions as to whether or not the students should know the 'correct' answer and (2) to instruct them as to how and where the missing information should be identified and reconstructed in prior talk. Teachers seem to trust and rely on the students' ability to recognize these conventions of question construction which will guide them towards the 'correct' answer and its expected format.

Therefore, when looking at the two formats which the answers may take, a distinction can be made between levels of recognizability the teacher accords to the expected answer. Some question formats instruct students precisely on the content of the answer which is embedded in the talk and there for them to perceive, thus conveying a sense of obviousness in the question. Other formats, by contrast, characterize questions which have far less transparent answers and, thus, involve more perspicacious respondents. Questions of the first set seem more frequently to engender choral answers, while the other formats produce bids to answer.

The idea that a certain level of obviousness is intrinsic to some definite features of the design of questions is related to the in-unison aspect. The presence of in-unison responses suggests that the answerers judge them to be logically projectable from that which comes before. The implication is that this recognition occurs for all members of the audience, and at the same time, causing them to act together as a whole body. This article will explore the ways in which this sense of the obvious is constructed and understood by the participants, and it will show how this process is crucial for an 
orderly progression of the interaction.

\section{Data and method}

The article illustrates part of the results of a larger study which was conducted in a primary school in a major industrial city in the north of Italy. The school actually serves one of the areas located immediately outside the city centre. Most of the community is composed of working and middle class inhabitants with a growing population of recent immigrant families who come primarily from China and northern Africa (Morocco, Algeria and Tunisia).

The school provides a full-time teaching programme to pupils from the age of 6 to 11. Students are present in the classroom for eight hours a day. Each year group is taught by two teachers who are present in alternation. In this school, as in the majority of primary schools in Italy, children regularly spend most of the school day in the same room, where almost all the subjects are taught. Students only leave the room for foreign language lessons, physical education, meals and extra activities. The data in this corpus includes only those activities that are carried out inside the classroom.

For the study I examined two third-year groups (ages 7-8) with around 50 pupils and their four teachers. The teachers who participated in this study adopt traditional teacher-led methods of instruction and forms of classroom management. Most of the time, and particularly during the preliminary phase of the lesson, the teacher faces the children, who are seated in parallel rows, and addresses the whole class. For these reasons I used two cameras in each classroom, so as to capture the participants' conduct as much as possible, from each party's point of view. The cameras were placed and switched on before the beginning of the morning lessons and kept going the entire time ( 8 hours a day). I was never present during the recording; both students and teachers saw me infrequently when I 
manipulated the cameras before or after the lessons. The recordings lasted one week for each of the two groups.

For the purpose of this specific study, the analysis will focus on excerpts from ten lessons. The examples examined belong to the phase in which the teacher presents the topic of the lesson, a moment in which the interaction is always teacher-led. In these sessions of talk, key notions are presented, ideas relating to the main topics of the lesson are discussed, and specific procedures are practiced for the solutions of problems or other pedagogic tasks. The core instructional sequences have been transcribed according to the conventions developed by Gail Jefferson (Atkinson and Heritage, 1984: ix-xvi) ${ }^{\mathrm{ii}}$.

The analytical approach is that of conversation analysis, which seeks to describe the methodical practices that people use in their social activities. Drawing from the work of ethno-methodologists, the method aims at discovering the ways in which members in a social setting make sense of their affairs as intelligible and accountable (Garfinkel, 1967: 33-34), with the accountability being grounded on the orderliness of the verbal and non-verbal practices of speakers. Thus, like any speaker who interprets the conduct of a co-participant in any ordinary conversation, and who considers social behavior to be an organized activity with recurrent and systematic features (Heritage, 1984: 241), teachers and students produce their conduct and interpret that of others on the basis of their sense of what instructing and being instructed in a formal setting is like. The primary place where speakers display how they view other members' behavior as orderly and accountable is the "subsequent action" (Heritage, 1984: 245). Analyzing the details of the construction of answers makes visible the respondent's interpretation of the question and the motives of the questioner. Thus conversation analysis can be described as the adoption of a sequential approach to the investigation of interaction. Indeed, several studies in the tradition of conversation analysis have been conducted on question-answer sequences in other institutional settings such as medical interactions (Frankel, 1983), courtrooms (Atkinson and Drew, 1979; Drew, 1992), and news interviews (Heritage and Roth, 1995; Clayman and Heritage, 2002), as well as classroom 
interaction (McHoul, 1978, 1990; Mehan, 1979; Drew 1981).

In the light of these considerations, the approach adopted here focuses on questions and answers which are produced in classroom interaction as a linked pair of actions, investigating the relationship between question design and interactional uptake. Through the examination of the details of verbal and non-verbal conduct of teachers and students in questioning and answering, the analysis aims to discover what conventions in the construction of questions are recurrently produced by the teachers and understood by students as engendering one or the other format which answers may take.

\section{The distribution of question types and answering uptakes.}

Investigation of the larger corpus of instructional sequences reveals that interrogative syntax is not the only resource used by teachers to ask questions. In $42.3 \%$ of the cases in a sample of the whole corpus, turn transfers between the teacher and the students are accomplished without implementing any syntactic structure code-able as interrogative ${ }^{\mathrm{iii}}$. For instance, sometimes teachers use declarativeformatted turns to accomplish the pragmatic force of interrogatives ${ }^{\mathrm{iv}}$, as evidenced by the typical answer format (line 4) and the bid (line 3) that follow the teacher's statement (line 1) in the fragment below:

(7) Small towns [PM:FZ:12.geography/Towns]

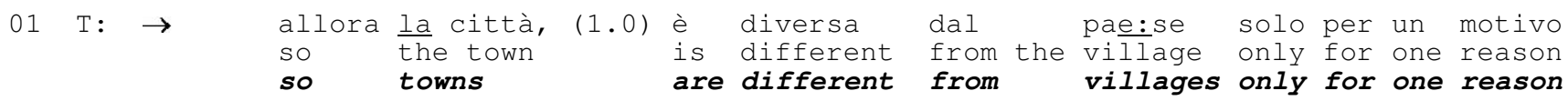


02 Fa:

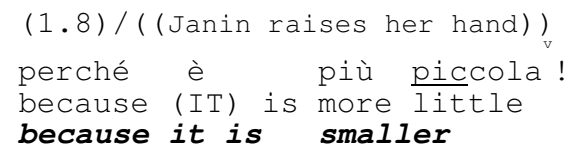

The practice of producing an incomplete turn (Fragment 1) is another non-interrogative type of questioning constructed mainly through the use of prosodic features.

The table below reports the figures based on the sample of data that includes four fairly extended instructional sequences and 156 instances of teachers' questioning turns and relative turn transfers to students.

\section{Table 1}

\begin{tabular}{|lc}
\hline Interrogative syntactic formats & \\
Yes/no questions & $15.4 \%$ \\
Alternative (or) questions & $5.7 \%$ \\
Open (wh) questions & $36.5 \%$ \\
\hline Non-Interrogative formats & $3 \%$ \\
Rear-loaded wh- questions & $25 \%$ \\
Incomplete utterances (Eliciting Completion Device) & $0.3 \%$ \\
Sub-sentential units ('appendor questions') & $2.5 \%$ \\
If-formatted utterances & $2.5 \%$ \\
Statements & $9 \%$ \\
Directives, Nominating \& Other Speaker management devices
\end{tabular}

As the table shows, the most frequent type is the open question $(36.5 \%)$, followed by instances of incomplete utterances as in the ECD (25\%), yes-no questions (15.4\%) and alternative questions (5.7\%). From the investigation of the answers to non-addressed questioning turns that belong to the four categories above, it emerges that choral answers tend to be produced more frequently after instances in which the questioning is accomplished through the $E C D$, yes/no and alternative interrogatives. Quite differently, the largest group of questions, represented by the wh-interrogative type, can engender both 
alternative responses: choral answers and bids to answer, with a predominance for the latter format.

This distribution of the two answer types shows that beyond syntax, there are other components of different questioning formats that cue student's understandings of how they are to answer. In the analysis that follows, I consider component units of the questioning turn, the placement of interrogatives within these turn constructional units, the placement of questioning turns inside the larger sequence as well as prosodic features and non-verbal aspects in the delivery of talk. I focus first on instances of the ECD, yes/no and alternative questions, followed by an analysis of whinterrogatives.

The quantification of questioning formats of teachers' turns of the sample, as illustrated in Table 1 , is included here to show that questioning in classroom instructional sequences is only partially describable by means of commonly established grammar categories and that other types of linguistic

organization are needed and, indeed, normally used by speakers to embody this conduct. ${ }^{\mathrm{vi}}$ It should be made clear, therefore, that the central focus of this investigation is to provide a description of the questioning practices, as they are produced and understood by participants, following an inductive procedure of analysis. Thus, the examples described in this study have been selected as the most illustrative of a wide range of cases that includes both clear examples and marginal or peripheral cases, so as to display the systematic practices used by the speakers to enact their courses of action.

\section{The Eliciting Completion Device: making projectable the missing item}

Table 1 shows that the ECD is one of the most frequent practices that teachers use to accomplish questioning without employing a specific interrogative format. In fragment 1 , we noted that this practice is implemented through the use of a cluster of prosodic features which are deployed in the vicinity of the withholding of the utterance's last component, as indicated in the gap of silence which follows the incomplete turn. The following extracts (8-15) show how this practice is recurrently 
produced. In approaching the last item of a turn, the teacher uses prosodic features such as intonation, sound stretching, and pitch contour to instruct students on the format and content of the item that will be missing. The device consists in an intense use of prosody in approaching the pause so as (i) to highlight that the topical focus is forthcoming, and (ii) to show how the flow of talk can be analyzed as being made of a series of components (words, syllables, sounds, etc) of the same type which is expected the students would provide as completion. With reference to this latter point, the teacher explicitly refers to the compositional pattern of the talk, thus providing a method for analysing it into its component parts, in addition to supplying a recognizable place for the students to provide the completion (Lerner, 1991). So, for instance, in fragment 8, by repeatedly using a significant rise of intonation in the last two words (line 3 ) before the pause in line 4, the teacher signals to students that a completion is expected and that the missing item is the word which would complete the utterance:

(8) Angles (PM:LT:5a.geometry)

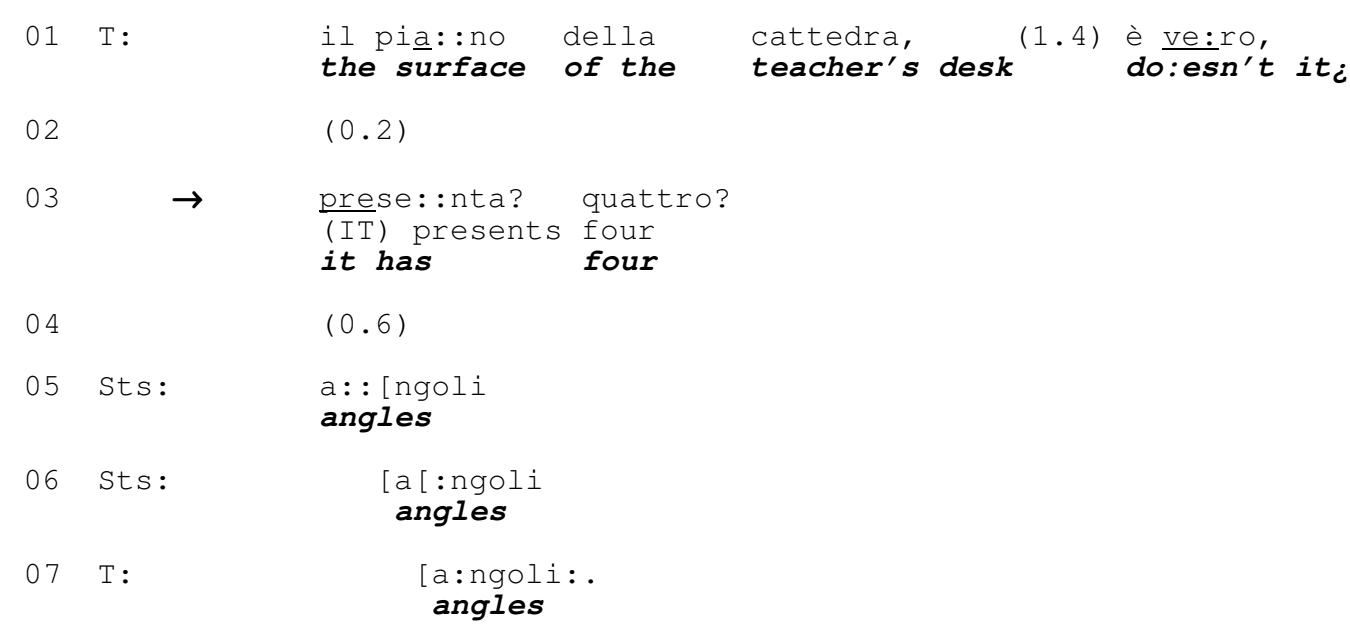

In the fragment below, the stretching of the vowel sounds and the emphasis which is produced in the first two syllables of the Italian three-syllable word ('ve-ner-dì') for 'Friday' alerts the students that the third and last syllable would be missing and left for them to be produced, which they indeed do in line 3:

(9) Friday [PM:FZ:22.geography] 


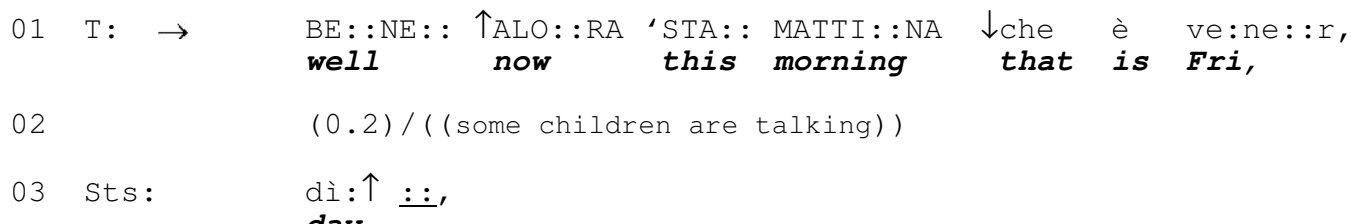

In fragment 10, through the emphatic production of the preposition 'di' and the micropause which separates the preposition from the noun, the teacher conveys that a relevant point will be made. This is followed by the production of the first syllable of the Italian word 'lavoro' for 'work', which the students then complete in lines 3 and 4 :

(10) Work [PM:FZ:12b.geography]

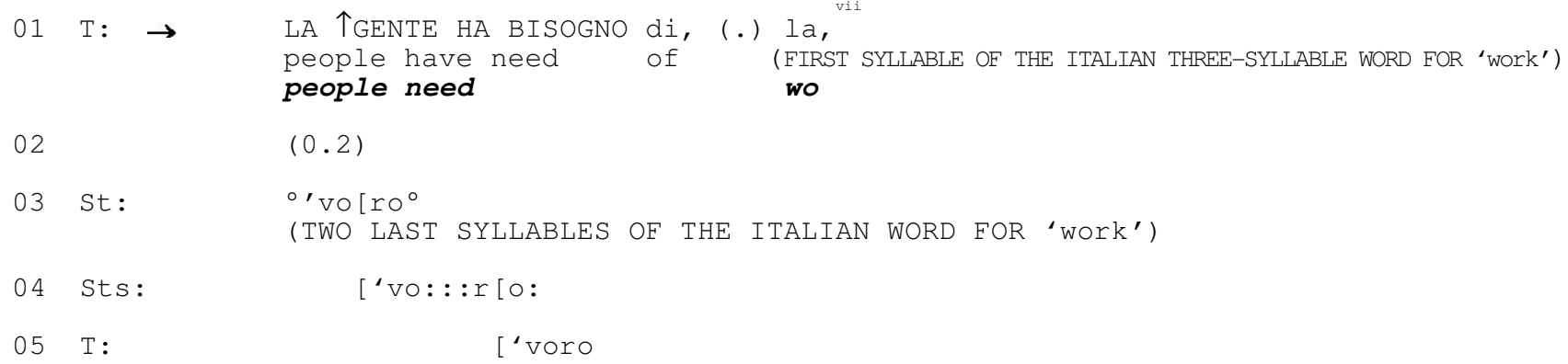

In fragment 11, in each of the arrowed lines, the teacher uses again these prosodic devices to section the flow of talk into its components so as to alert the students on the type of item that they would have to provide in order to complete the utterance. By stopping for the time of a micropause after the verb 'to be' (line 1) -which is also delivered with emphasis, the teacher is projecting a forthcoming relevant point in talk. Similarly to example 8, the use of a rising contour partitions the flow of talk into its components, alerting the students to the fact that they should complete the utterance with the last item. In line 1 the item requested is the word 'rotation'. But, in line 3, the teacher produces a further partition of the word 'rotation' into its syllable-components by stretching the vowel sounds of each syllable, which is also delivered with emphasis. In this way the students are instructed on the format of the item which is missing and which they provide in line 4.

(11) Rotation [PM:LT:5b.geometry/angles]

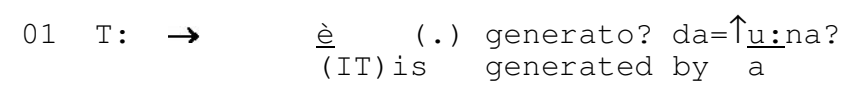




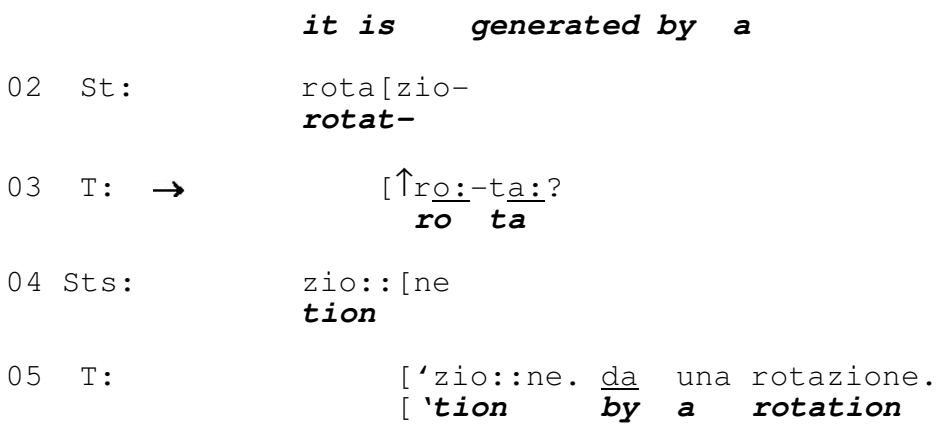

The case of example 11 and, in particular, the occurrence of the answer produced by one student (line 2), before the choral answer in line 4 (other similar cases are in line 3, fragment 10 and 14), needs some further specification with regards to our claim that the ECD is frequently followed by choral answers. As a matter of fact, the answer given by the single student in line 2 could be viewed as contradicting our point. However, if we do not confine our analysis to line 2 and go on to consider also the teacher's following turn and the progress of the sequence, we see that the student's answer is treated by the teacher as a departure from the general pattern, which displays her orientation to the ECD as normatively implying an answer in chorus. Thus, we can notice that in line 3, the teacher's turn overlaps the prior individual answer by starting at the third beat of the projected word. As illustrated also in the prior example (10), when the production by a single student reaches the third syllable, the word is likely to be recognized by the majority of the other students, who thus furnish completion (line 4). With the word 'rotation' (example 11), however, the students seem to hesitate to recognize the exact word or to understand that a choral answer is expected at this point. The latter, at least, appears to be the case here. The teacher's turn in line 3, in fact, does not add anything more to the prior student's production; on the contrary, it leaves out the third syllable, which the student has previously produced in line 2 . Another indication that the teacher is oriented to a choral production the fact that she provides the third-turn positive evaluation of the answer only after the choral answer (line 5) and not after line 2, although the syllables produced clearly indicate that the student was hinting at the correct completion. 
The ECD is rather frequently associated with other types of interrogatives and may function to draw the students' attention to the upcoming topical focus of the following question, as in fragment 12 below. The questioning turn has the shape of an alternative question which is also preceded by a whquestion (b-arrow). It appears that, in the course of delivering the word 'temperature' the teacher realizes that there is a further opportunity to elicit the students' participation. The word 'temperature' is thus produced in the manner of the ECD (a-arrow).

(12) Temperature [PM:FZ:geography]

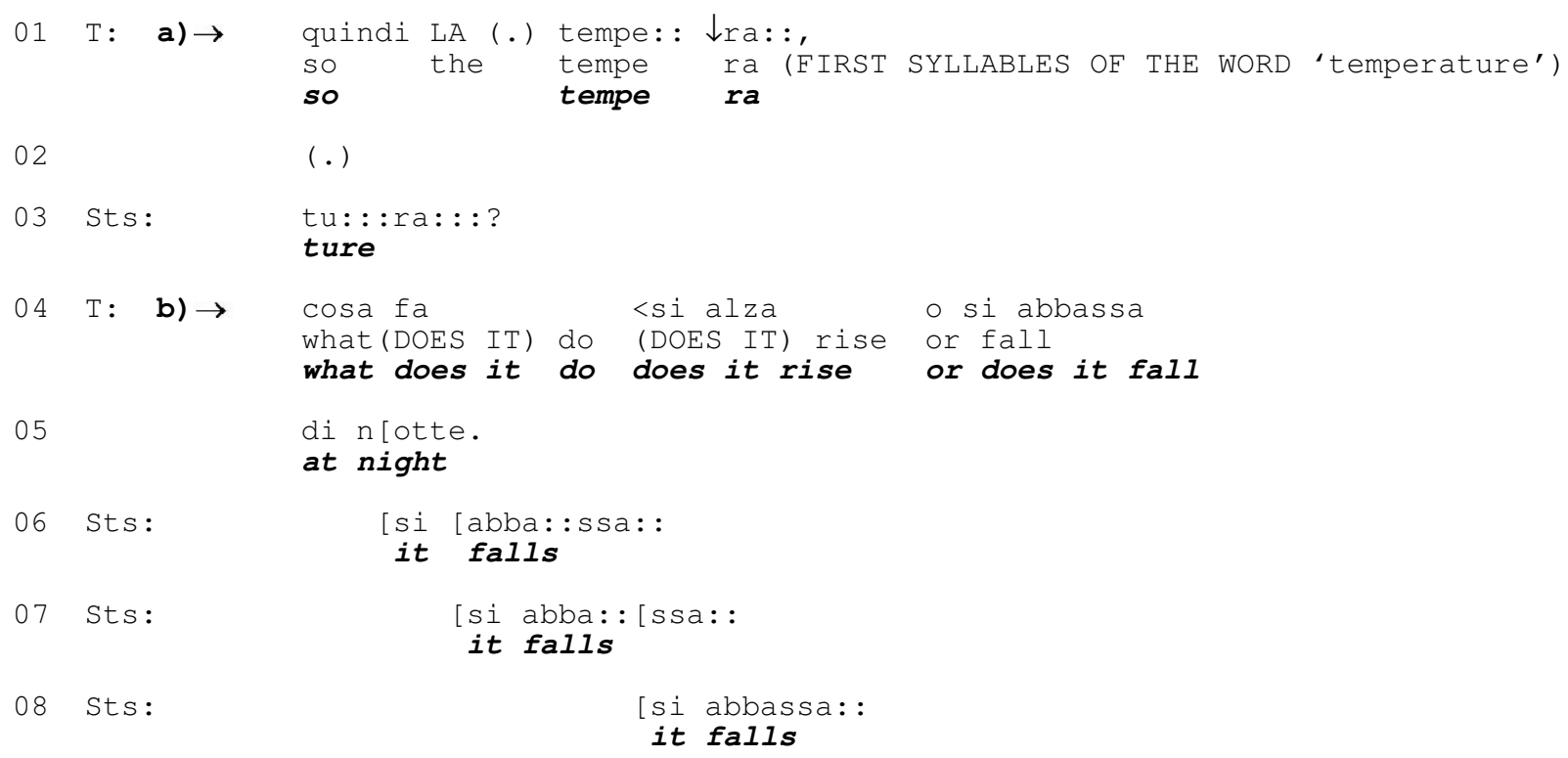

The students complete the utterance in perfect unison in line 3, after a micro-pause. This device serves as an invitation to the students to demonstrate that they are so attuned to the talk underway that the teacher can withhold any part of her talk and elicit completion from them.

It is clear that in cases like fragments 9 (line 1), 11 (line 3), and 12 (line 1), where the item to be completed is a multi-syllable word and only its final syllables are left unspoken, the word is already clearly recognizable when it gets interrupted (as in Venerdi). Furthermore, in (9) the syllable-bysyllable delivery of the part of the word which is spoken provides the recipients with a clearer model for analyzing the flow of talk into its phonological components and thus to project those which are left 
unspoken. ${ }^{\text {viii }}$ Projecting the final part of a multi-syllable word is a much easier task than projecting larger units which are more difficult to reconstruct from the information provided in the preceding turn constructional unit.

Fragments 1 and 11 (line 1) demonstrate, however, that the ECD might also involve larger units than just a few syllables. In some instances, the item which is designed as missing can be an entire word, a phrase, a clause, or a sentence. But, when teachers withhold these larger units, the ECD is deployed in precise sequential positions with reference to prior talk: the teacher elicits the completion only when the item has been already provided in recent prior talk.

Fragment 13 below illustrates a larger sequence which includes, as its final part, the reproduction of fragment 11 (lines 8-12). This sequence demonstrates how the teacher progressively supplies more and more of the desired answer, leading up to the collective recognition of the expected completion.

(13) Direction [PM:LT:5b.geometry/angles]

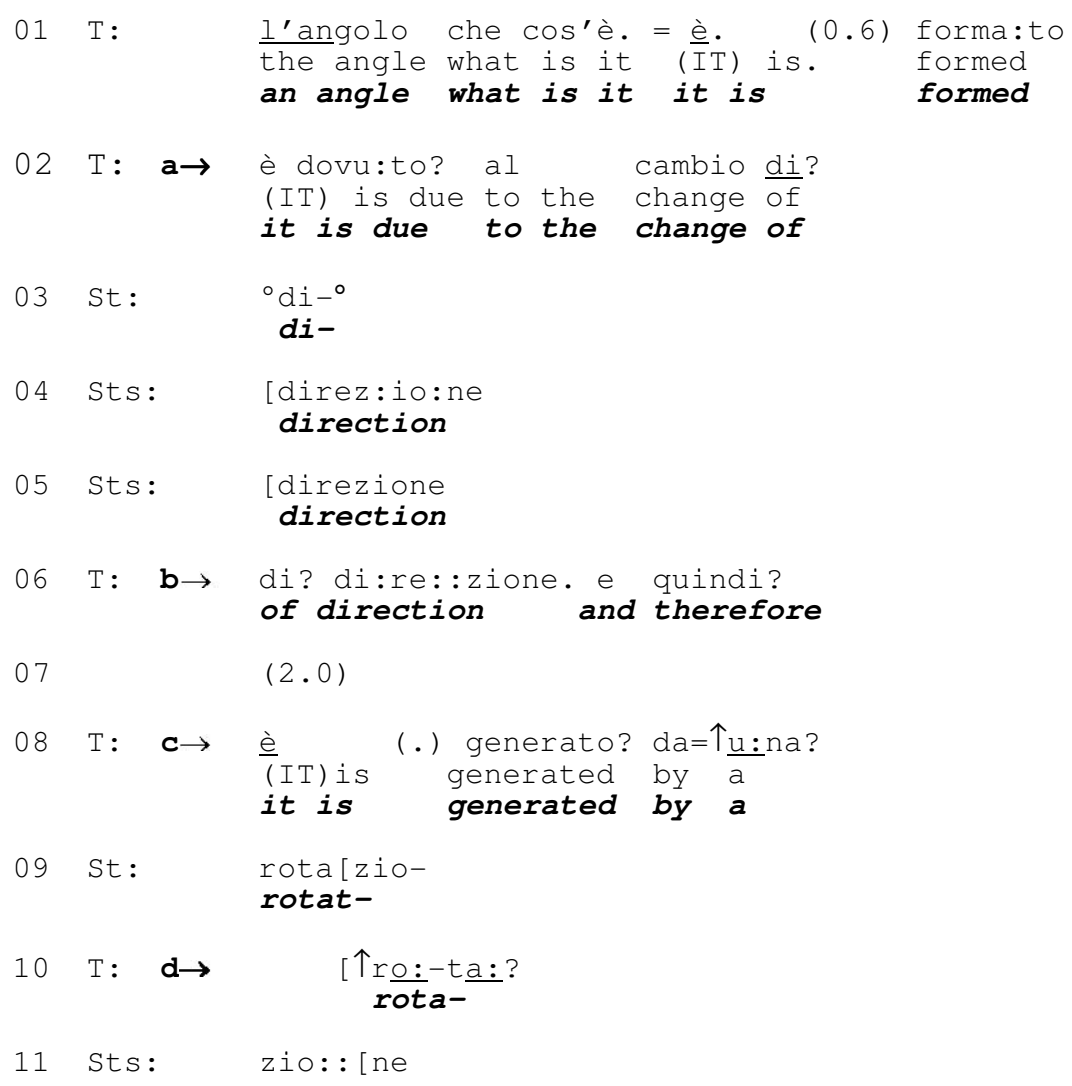




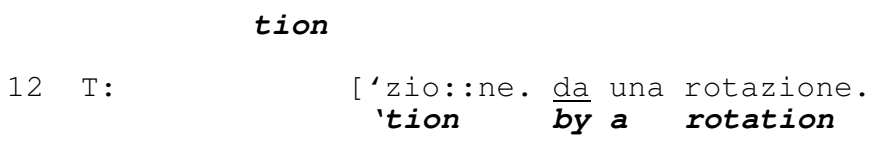

The arrowed lines indicate instances in which the teacher produces the ECD. Each time, with the exception of the last one (line 10), the missing item is not easily projectable from what immediately precedes it in the incomplete turn. In line 2 the word 'direction' is missing, while in line 6 the teacher apparently elicits an entire sentence, which is indeed produced later by the same teacher in line 8 .

Finally, the turn in line 8 is left incomplete because the word 'rotation' is left unspoken.

In fact, the request to provide such less projectable units is often produced so as to make the students use repetition or a quotation from prior talk. For example, both words ('direction’ and 'rotation') and the sentence ('it is originated by a rotation'), which are all missing in fragment 14 , have been produced earlier on, quite recently. In the following transcript, prior occurrences of the missing items are indicated by the letters in the margin. This sequence actually preceded the talk in 13 .

(14) Rotation[PM:LT:6b.geometry/angles]

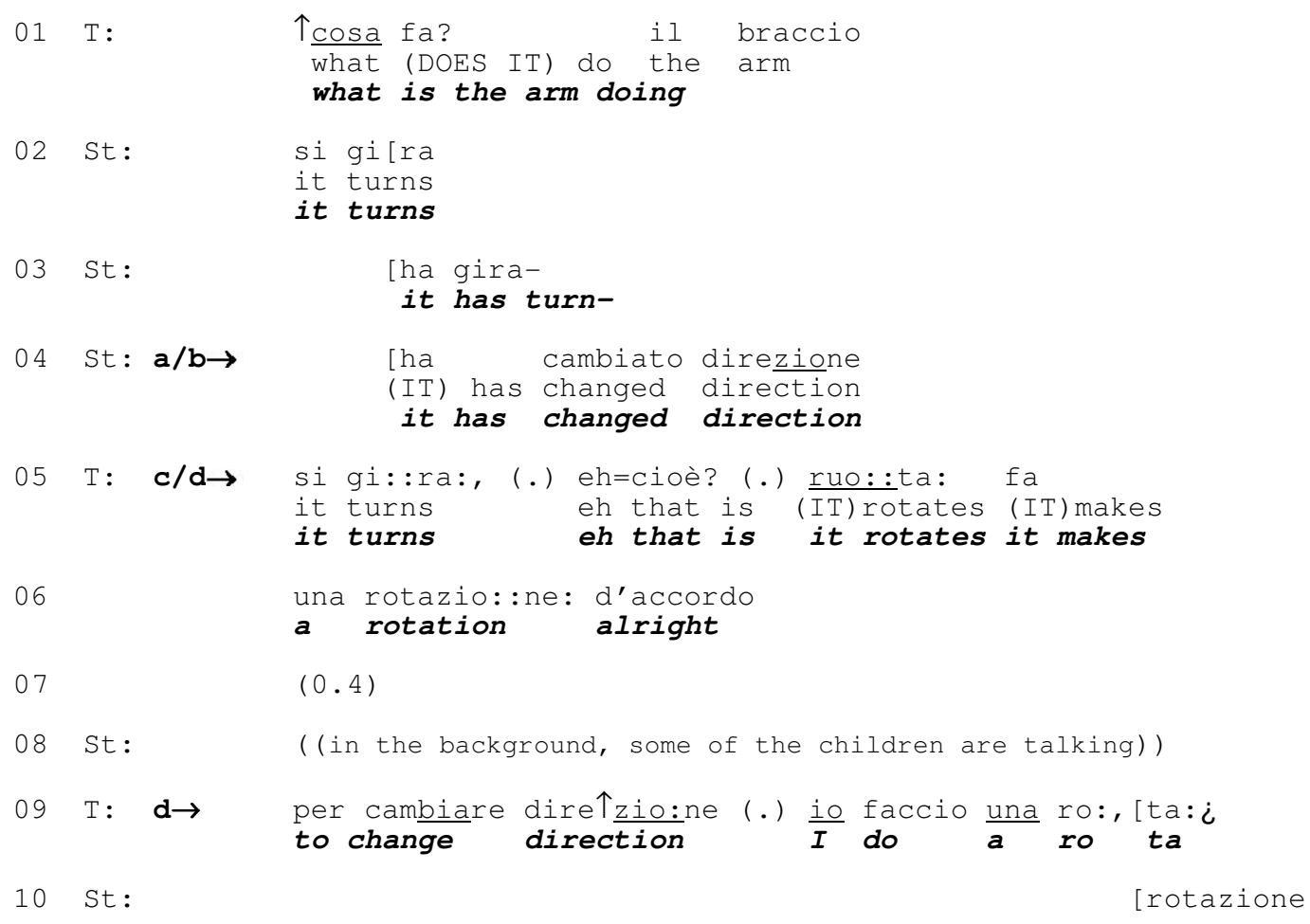


$\begin{array}{ll}11 \mathrm{~T}: & \text { zio: : ne. } \\ & \text { tion }\end{array}$

In lines 4 and 9 the word 'direction' is used in the same syntactic context ("it has changed direction") in which the word is elicited later in fragment 13 (line 2). Then, in lines 5, 6, and 9 above, the teacher produces the word 'rotation' and the verb 'to rotate' several times along with the explanation. Hence, it is clear that the later requests to provide the two words in fragment 14 (lines 2 and 8), as well as the sentence withholding (line 6), all build upon the earlier occurrences of these same items in prior talk.

This is made possible by means of two main practices. (1) When the teacher withholds part of one word, the syllable-by-syllable enunciation projects the missing item as a turn-constructional unitin-progress (Lerner, 1991), which is interrupted only when the word is made recognizable to recipients. (2) When withholding larger and less projectable units (an entire word, phrases, clauses, sentences), the teacher deploys the unfinished turn after some prior occurrences of the missing item. In this way students are instructed that, in order to complete the turn, a recycling of information from prior talk is requested.

We can conclude this section by observing that inviting completion through ECD is a precise instructional technique that enables students to analyze the talk underway so as to recognize exactly what is missing, as well as where and how it can be found in the talk that is left unspoken. In this way, finishing the teacher's turn is built as a highly predictable and, consequently, obvious task. This transparency is evidenced by the choral production. It is also clear that, through the eliciting of precise types of responses, teacher and students collaboratively assemble pieces of knowledge on which talk further progresses. In this way, a precise instructional aim is achieved via interactional practices. 


\section{The alternative interrogative type: choosing the right option}

The use of alternative interrogatives to instruct students as to the 'correct' answer depends on other resources and is obviously grounded in the two-part structure, typical of this format, in which both possible alternative answers are explicitly expressed. Fragment 15 is one such case. The grammatical format of the question is constructed so as to contain the explicit formulation of the two possible answers: "does the temperature rise or does it fall?"

(15) Temperature [PM:FZ:geography]

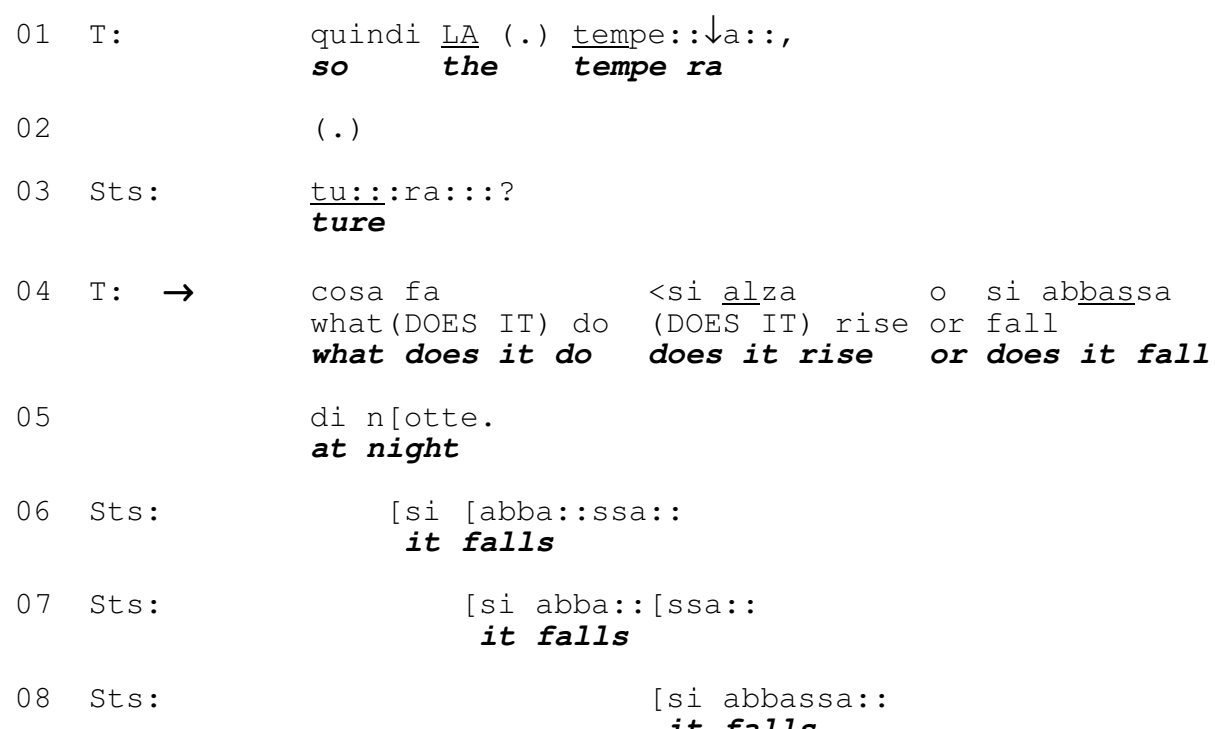

The three excerpts below are further examples of this structure:

(16) Rivers [PM:FZ:12b.geography]

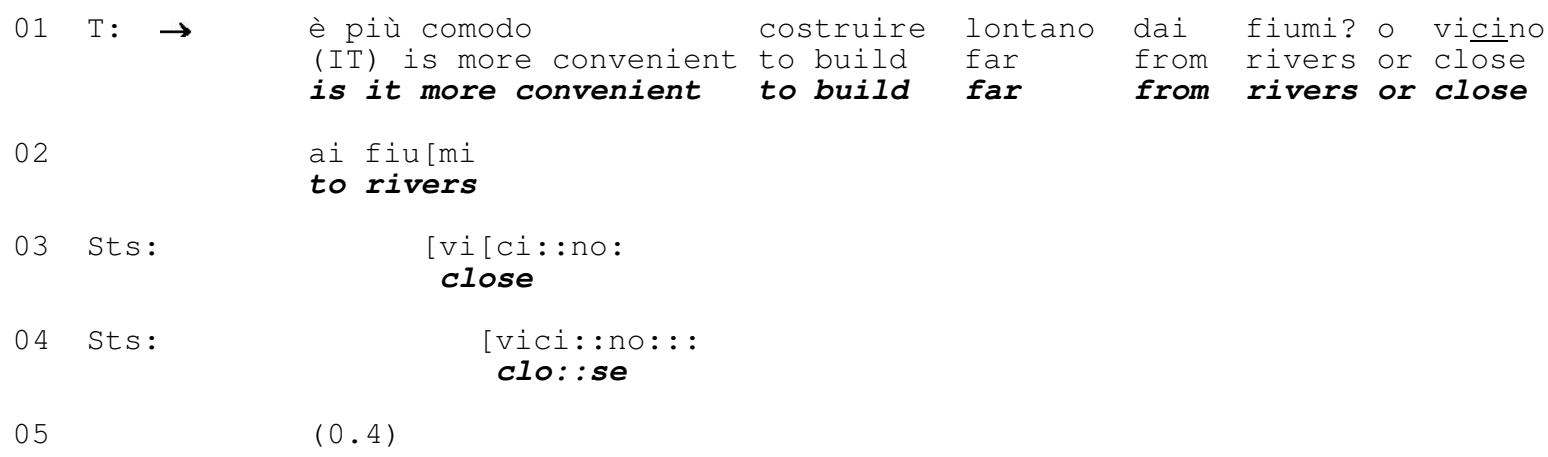


(17) Roads [PM:FZ:12b.geography]

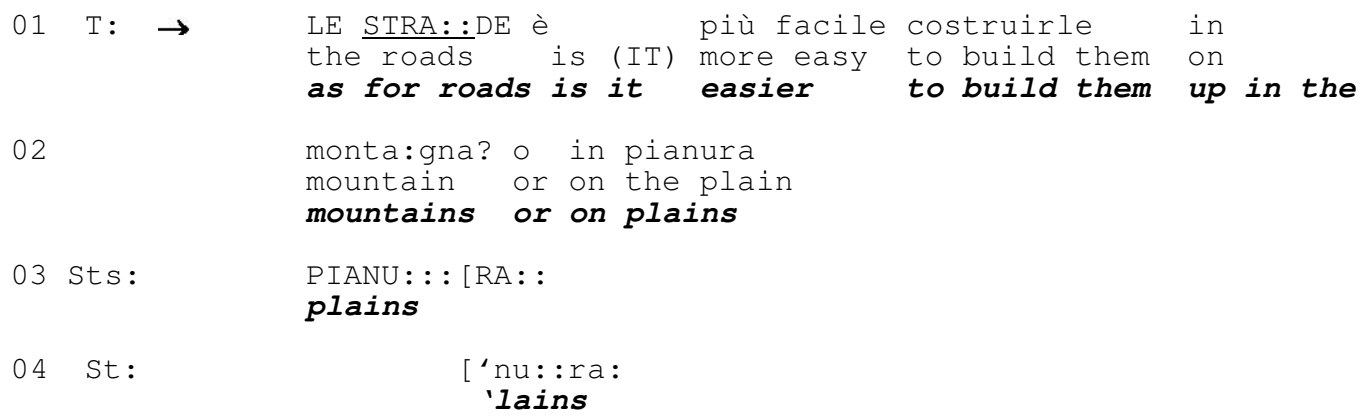

(18) Open or closed [PM:LT:5:geometry]

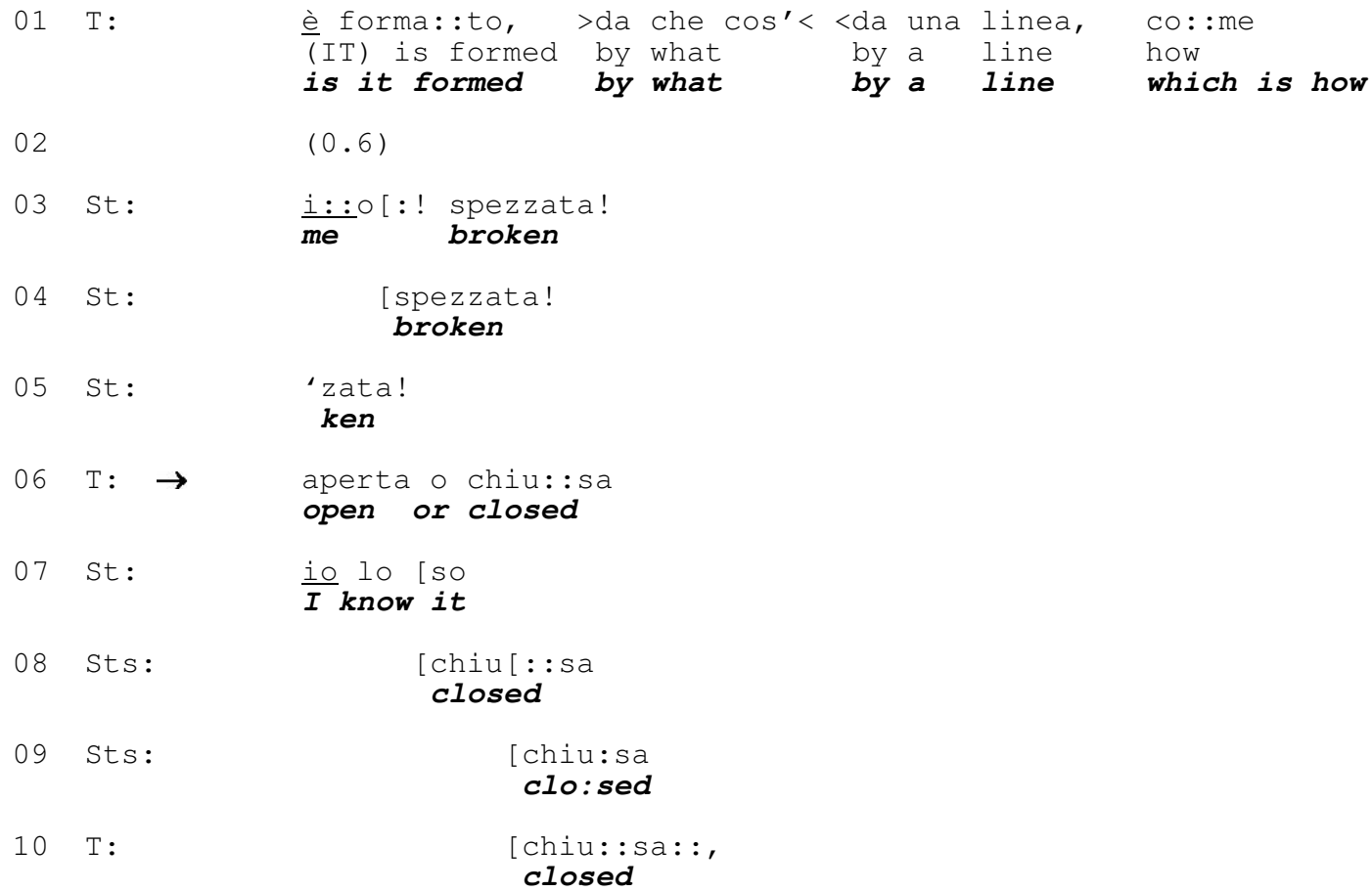

As the transcripts make immediately evident the questions have a regular pattern insofar as the candidate answer occupies the final position. This is apparently related to the students' choral repetitions of the second alternative, which is the expected answer.

The instructional force of this interrogative pattern, the projection of the second component and the consequent instruction to recipients as to the answer, is well evidenced in the fragment below. 
Before the teacher actually formulates the second alternative option (line 4), drawing from the lexical and prosodic properties of the first part of the question, some students are able to project exactly what will come next and offer the answer right away, without waiting for the teacher to finish the turn.

(19) Table of addition [PM:LT:3: maths]

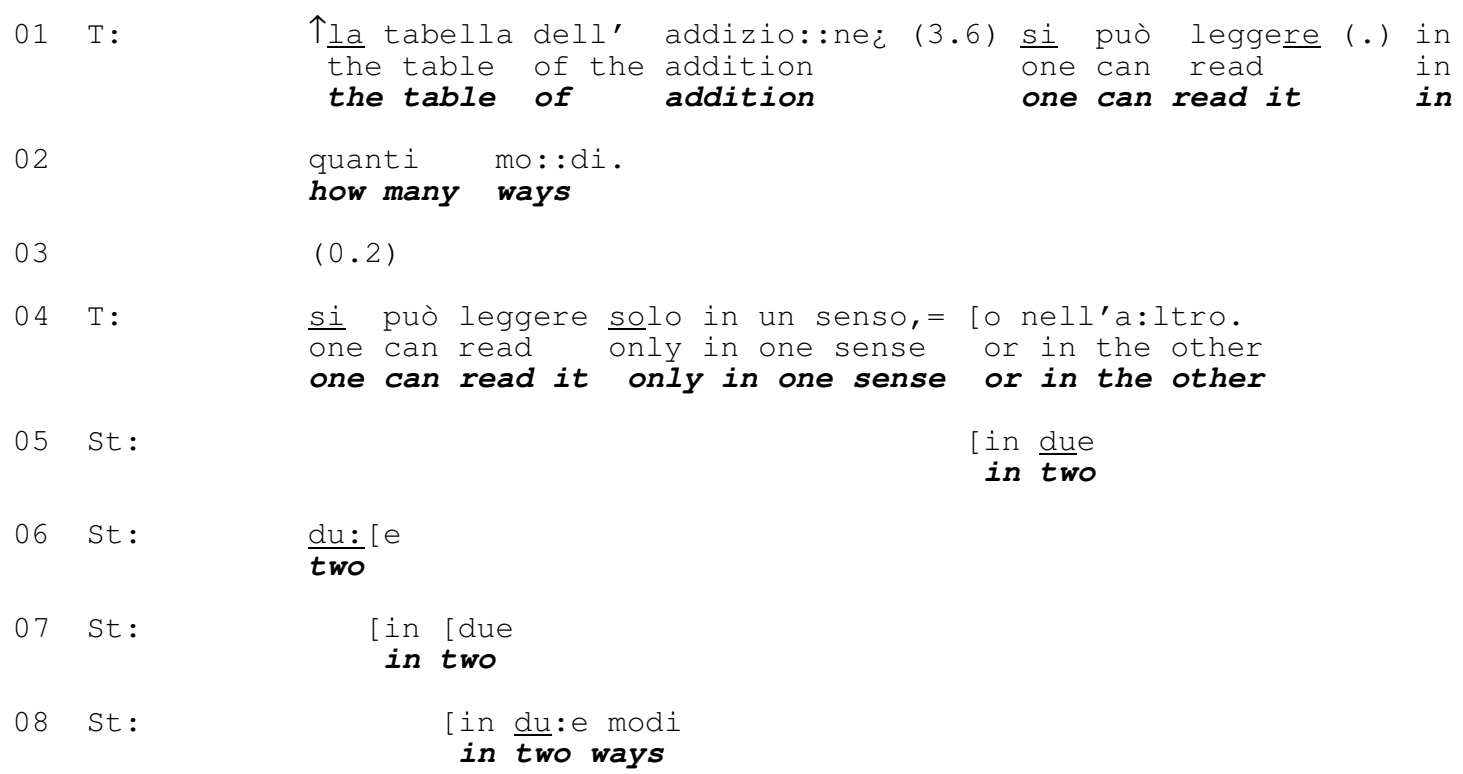

The use of the quantifier ('uno' / 'one') in association with the intensifier ('solo' / 'only') creates the expectation of a forthcoming contrasting formulation, which is indeed readily anticipated in lines 5 to 8 by some students.

However, not all questions of this type follow the pattern of placing the correct answer in the second position, as we see in extract 20 , which also generates a correct, choral response.

(20) Plains [PM:FZ:12b.geography]

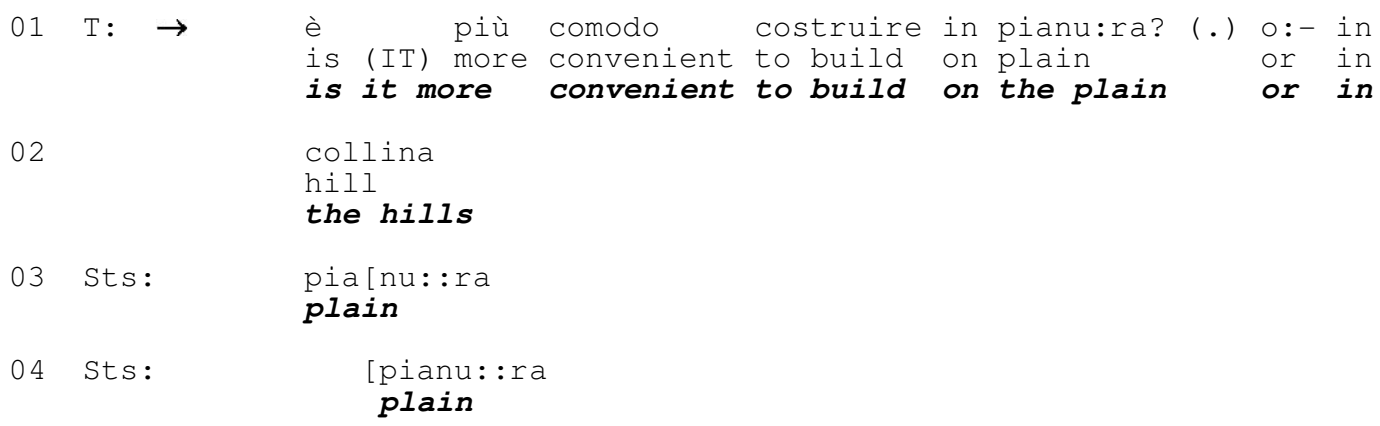


As discussed in Heritage (1984: 248-251), the consideration of 'deviant' cases and of the detailed way in which these are differently implemented provides stronger evidence that speakers orient to the requirement of the phenomenon as normative. With respect to extract 20 , we find that the reverse order is associated with some prosodic features produced by the teacher when approaching the second part of the interrogative. A micropause and a cutoff follow the first part; furthermore, the conjunction 'or', which links the two misplaced parts, is also prosodically marked by sound stretching. These features suggest that the teacher might be catching the reversed construction of the utterance before it reaches completion and, thus, possibly suppressing an incipient self-repairing (Scheloff, Sacks and Jefferson, 1977). Although the case for a self-repair here can be rather speculative, owing to the fact that it isn't actually accomplished, these disfluencies act as resources which convey the teacher's negative stance towards the actual progression of the question design and, consequently, mark the second component as incorrect.

In conclusion, we can argue that in alternative interrogatives, in order to make the students arrive at an understanding of the correct answer, teachers and students employ and interpret the potentialities that the grammatical format offers as well as its possible constructional variations. In addition, teachers employ prosodic features of turn delivery to clarify their stance toward the question and its preferred answer. Through these devices - syntactical and prosodic - the teacher instructs the students as to the content of the expected answer.

\section{Yes-no questions and their preferred answers}

The format of yes-no interrogatives, like that of alternative questions, also reduces the possible responses to a choice between two possibilities, in this case 'yes' or 'no'. As Pomerantz (1988) argues, 
yes-no questions can be heard as incorporating the candidate answer in so far as the questioner provides the recipient with "just the information that is relevant to the immediate concern" (Pomerantz, 1988: 368). In ordinary conversation, yes-no questions are biased towards a positive or negative answer according to the interactional relevancies of the actions that are implemented through the questionanswer sequence (Schegloff, 1984 and 1995; Raymond, 2002).

In the classroom context, interrogatives are used to elicit new / retrieve known information from students, along with other institutionally specific actions, such as to repair / correct inappropriate or wrong answers (McHoul, 1990; Macbeth, 2004). Insofar as questioning in the class is designed to elicit a precise answer / piece of information, the activities implemented through question-answer sequences in this setting can be viewed as having some similarities with the courtroom case described in Pomerantz (1988). ${ }^{\text {ix }}$ In both settings it is important for the questioner to instruct the respondent on the expected answer.

The discussion which follows demonstrates that teachers design their questioning so as to provide the students with very clear indications as to whether the question is designed to project a 'no' or a 'yes'. In the fragments below, examples of yes-no questions are produced as they recurrently occur in my corpus, along with their answers. I have grouped some of the most representative instances in two sub-sets: yes-answer and no-answer questions.

To begin with, we will look at the yes-answer questions. Fragment 21 contains an interrogative delivery structure and some of the features of turn design that occur repeatedly throughout this section. (21) Human beings [PM:FZ:12:geography]

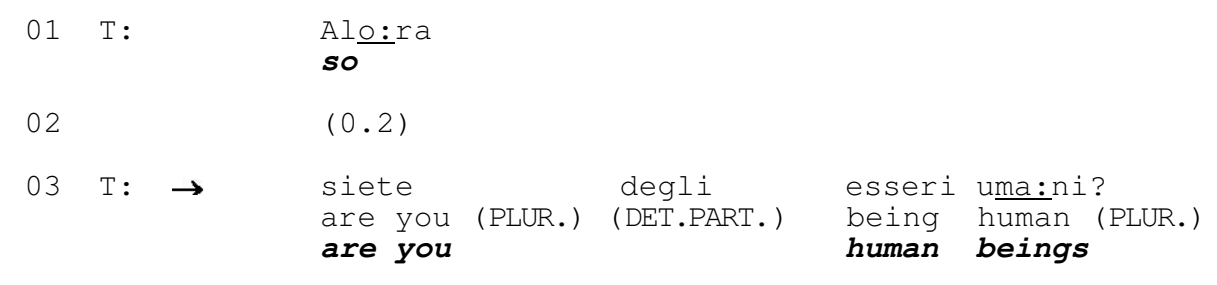


Three elements stand out. First of all, the questioning turn is prefaced by an introductory marker (line 1), which also works as a disjunctive element with reference to prior talk, proposing that a distinct sequence is thus being initiated. Furthermore, the questioning turn is a neat standing-alone interrogative unit (line 3) and, third, it makes relevant a choral affirmative response as the expected answer (line 4).

These features are observable in other excerpts of this type. The second fragment is from a lesson on mathematics. The class has to solve a problem of division. With the question in line 1 , the teacher is checking whether the students have understood which information is given and which is not. The number of containers, to which the teacher refers in line 1, is provided in the problem, which has just been read aloud. The questioning turn is composed of a single sentential unit and is deployed as one distinct question within a series of others, which are produced to check whether the students have understood the problem. The question, again, is positively answered:

(22) Containers [PM:FZ:21:maths]

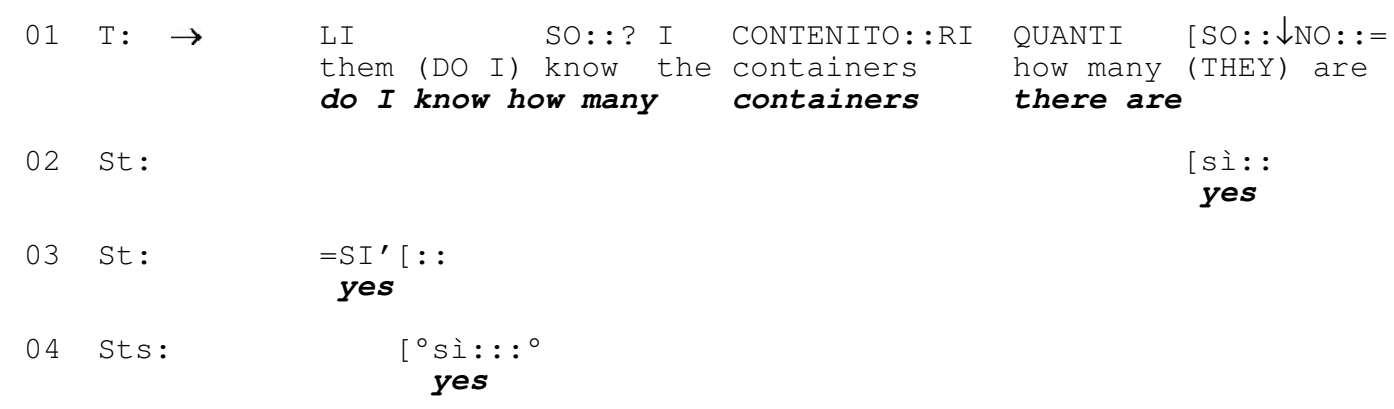

In the following excerpt the yes-no question again receives a positive answer. The question is introduced by a question preface ("according to you") that typically introduces a query and which, thus, initiates a first action. The questioning turn consists of a single utterance, and it is answered in unison. One student produces an anticipated answer in line 2, a second responds in overlap with the 
end of the teacher's turn (line 4), and finally the whole group answers in unison in line 5.

(23) Two groups [PM:LT:2:natural sciences]

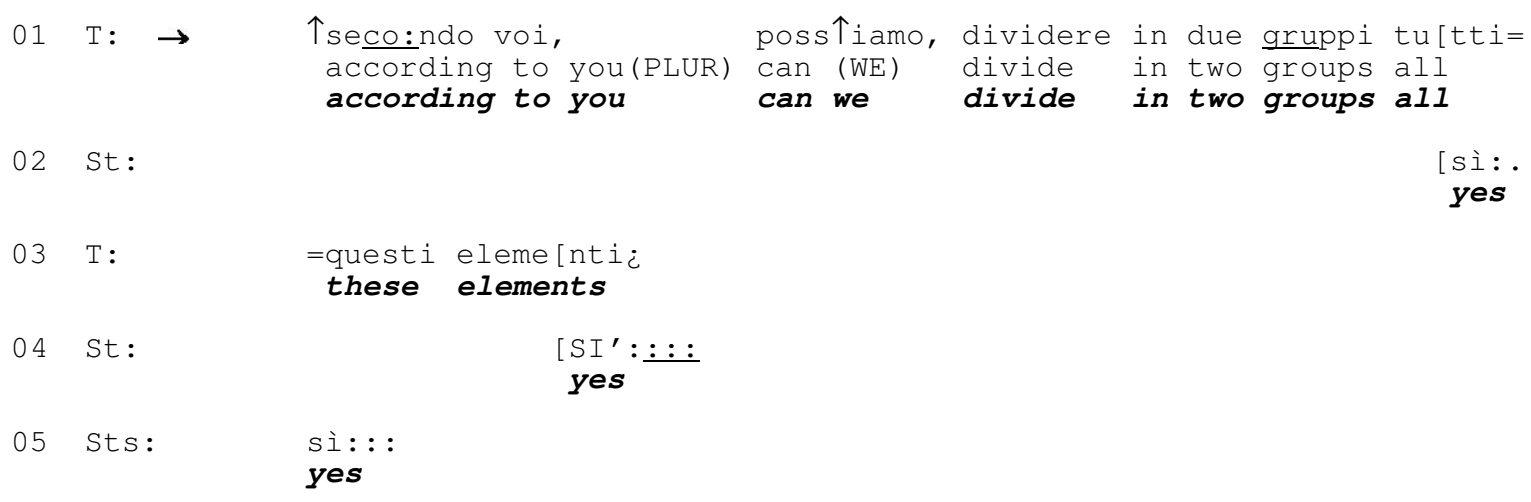

The examples show that there are precise features in the construction of yes-no questions that seem to yield choral yes-answers. These features become even more evident when compared with the fragments belonging to the second sub-set, in which students provide the opposite answer, but again with a choral delivery.

Excerpt 24 is from a lesson on mathematics on the properties of addition and subtraction. Prior to the exchange below, the teacher has formulated a question about the table of addition, which has received an in-unison positive answer. The 'table' mentioned in the question is a poster illustrating the properties of the two mathematical operations, which hangs on the wall. In the extract below the teacher then passes to examine the table of subtraction. And, indeed, the question yields choral negative answers:

(24) Subtraction [PM:LT:3:mathematics]

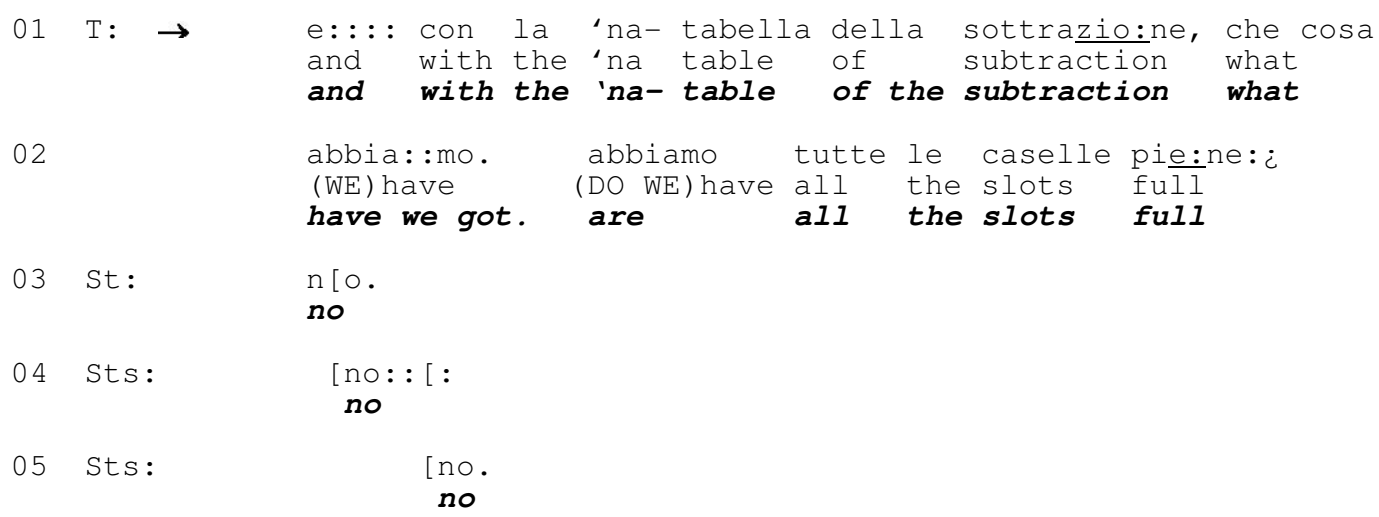




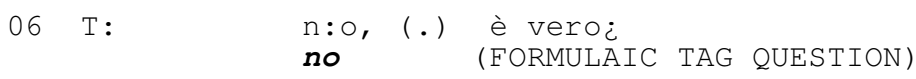

The design of the question turn in this fragment is clearly different from the design of that in the preceding fragments, yielding choral yes-answer.

First, while yes-answer questions are normally single units, the question in fragment 24 is a multi-unit turn. Three different formats are packaged to construct the questioning turn: (i) a subsentential unit which could be complete after 'subtraction', but which is not hearable as such, owing to the suspended intonation; (ii) a wh-interrogative ("what do we have") which is produced with a falling intonation; and (iii) a yes-no question ("are all the slots full"). Second, the whole three-unit questioning turn is deployed to be heard as another question in a series, as indicated by the conjunction 'and'; thus not as initiating a new sequence. As demonstrated by Heritage and Sorjonen (1994), and-prefaced questions convey the sense that a course of action is achieved through a series of question-answer pairs whose coherence is determined by the goal of the activity that is thus undertaken (ibid.: p. 4). Fragment 25 illustrates the question-answer sequence on addition, which preceded the sequence dedicated to subtraction in extract 24 :

(25) Addition [PM:LT:3:mathematics]

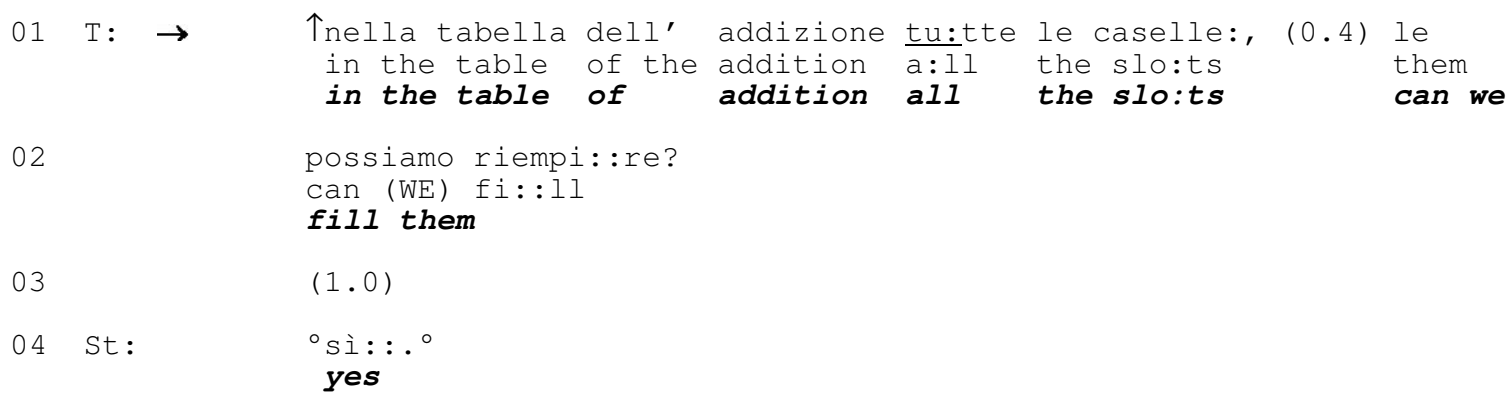

It is now clear that the conjunction 'and' which precedes the questioning turn in fragment 24 (line 1) is constructed by analogy with the question in line 1 ("and with the table of subtraction?") in the sequence that precedes it (fragment 25); thus presumably implying a question like the following: "and with the table of subtraction can we also fill all the slots as we did with the table of addition?". 
By comparing the format of the no-answer questioning format in excerpt 24 with that of the yes-answer questions in 25 , it emerges that while the former is hearable as drawing upon prior talk, in the case of yes-answer questions (fragments 21, 22, 23, and 25) the reverse is true. That is, these are usually deployed as single pieces of independent truth.

Another characteristic of the no-answer question (fragment 24) is the teacher's use of a quantifier when asking whether all the slots can be filled. In this regard it is useful to recall Labov's (1984) hypothesis on the way in which quantifiers (such as 'none' 'all', 'always' and the like) work as intensifiers in creating a cognitive contradiction that is implicit in the propositional content of the utterance $^{\mathrm{x}}$. In particular, here, the quantifier seems to convey the teacher's skepticism towards the propositional content of the talk. In general, the teacher's use of these elements in the construction of yes-no interrogatives conveys a negative stance towards the content of the question, thus instructing recipients that a negation is preferred. In other words, through this marked format, the teacher indicates that the candidate answer, which is incorporated within the questioning turn and explicitly formulated, is designed to be heard as wrong and, thus, to be negated.

A final characteristic of the no-answer question is the fact that the question that finally engenders the no-answer is deployed in the turn as a component unit following a prior open question, thus hearable as the implausible candidate answer for the prior open question. These features are evident in fragment 26:

(26) Temperature [PM:FZ:22.geography]

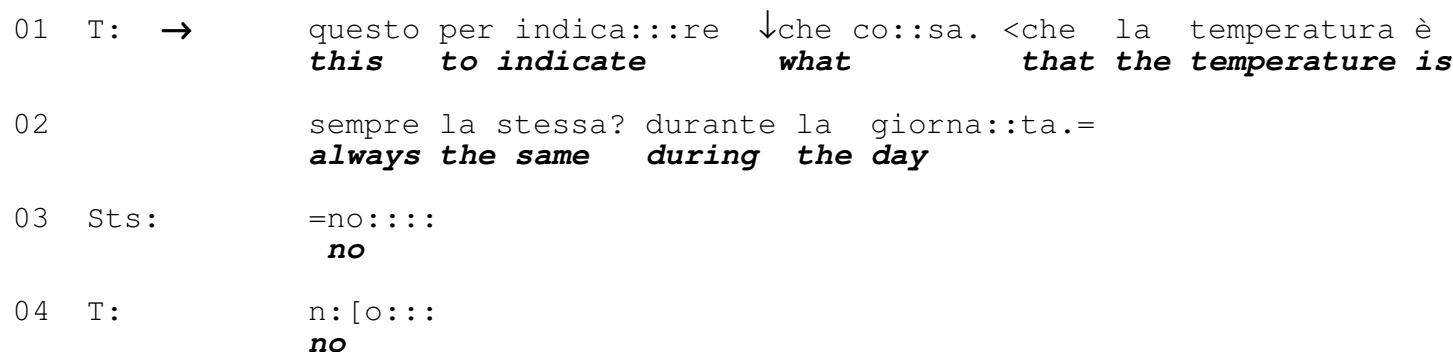


05 Sts:

$[$ no: : : :

no

Again, the teacher's turn is constructed as a multi-unit turn composed of two distinct interrogatives. This produces the rhetorical effect described above, whereby it is suggested that the questioner is skeptical and does not align to the propositional content of the questioning; and precisely to the last interrogative component ("the temperature is always the same") as being positively answerable. Again, the questioning turn is designed as connected to prior talk, as is indicated by the demonstrative pronoun ('this') that is located in first position and ties the question to a premise. Indeed, this initial item projects a declarative sentence, rather than an interrogative: in this way the teacher seems to be drawing some conclusions from prior talk, rather than initiating a new question-answer sequence. Finally, the teacher uses a quantifier ('always', line 2) to intensify the propositional content of the question which, as we have seen above, adds to the sense of skepticism and plays a crucial role in conveying the teacher's attitude towards the utterance as contrary to its propositional content.

To conclude this section, it is worth considering a further related case: an apparent irregularity (another 'deviant' case) which actually supports our interpretation. In the fragment below the teacher addresses the class with a yes-answer question which appears to be more problematic in terms of the projected correct answer:

(28) Beach [PM:EZ:12b: geography]

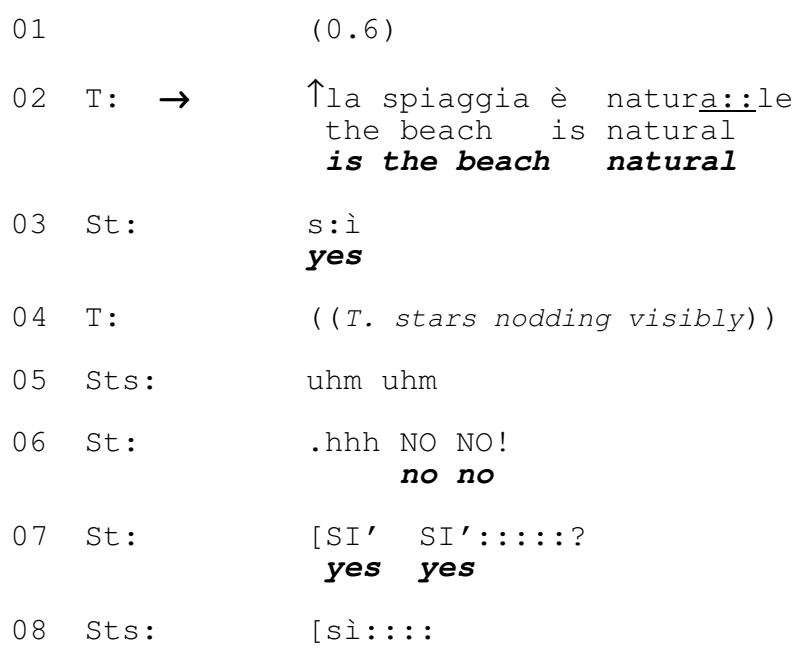


The conventions of the question construction adhere to the format we have describe as engendering a choral 'yes'. As in the fragments of the first sub-set, the teacher begins the turn after a considerable pause: an indication that a new question-answer sequence is thus beginning. In addition, the question key-item is produced with a distinctive high pitch in the first syllable, which foregrounds the 'questionable' in the turn and thus, again, projecting the beginning of a new question-answer sequence, somehow disjuncted from prior talk. Furthermore, the questioning turn is constructed as a standingalone single-unit interrogative. However, this time, the students do not all agree in providing the expected 'yes'.

But the fact that this format is precisely built to elicit a positive answer as its obvious uptake is made clear by the teacher's non-verbal behavior; she starts to nod visibly (line 4) as soon as it becomes evident that the majority of the students have problems in producing the expected answer. Thus, although this extract apparently contradicts what has been observed in the other fragments of the yesanswer set in so far as it does not elicit so successfully a choral answer, it nevertheless provides strong evidence of the association which we have established between some precise features that teachers employ in the construction of yes-no questions and their projected answers.

To conclude, we have observed that in the case of yes-no questions the presence or absence of some features produces contrasting patterns in the design of the questioning turn, which instruct the students to identify the correct answer among a set of alternative choices:

(i) the single-unit vs. the multi-unit composition of the questioning turn;

(ii) its being designed as connected or detached from prior talk;

(iii) the presence or absence of quantifiers, which indicate the teacher's stance towards the question. 


\section{Open questions and their different outcomes}

The sense of obviousness which is conveyed through the prosodic and syntactic features in the construction of questions is an important aspect of open interrogatives as well. With regards to this last group of questions (the largest in my corpus), this aspect is particularly crucial because both types choral answers and bids- are produced after open questions, although the latter types are more frequent. This might stem from the fact that open interrogatives, unlike the other formats analyzed so far, "expect a reply from an open range of replies" (Quirk et al., 1985: 806). This poses different constraints on the answer and, furthermore, on the options that teachers have at their disposal to instruct the students on the expected answer. Nonetheless, many features of the design of these interrogatives and of their sequential deployment, especially of open-questions associated with a choral outcome, are significant as further examples of questions that 'go for the obvious' in the classroom.

Fragment 28 is an example of the most frequent open-question pattern, which invites students to ask permission before answering.

(28) Medical substances [PM:FZ:12b:geography]

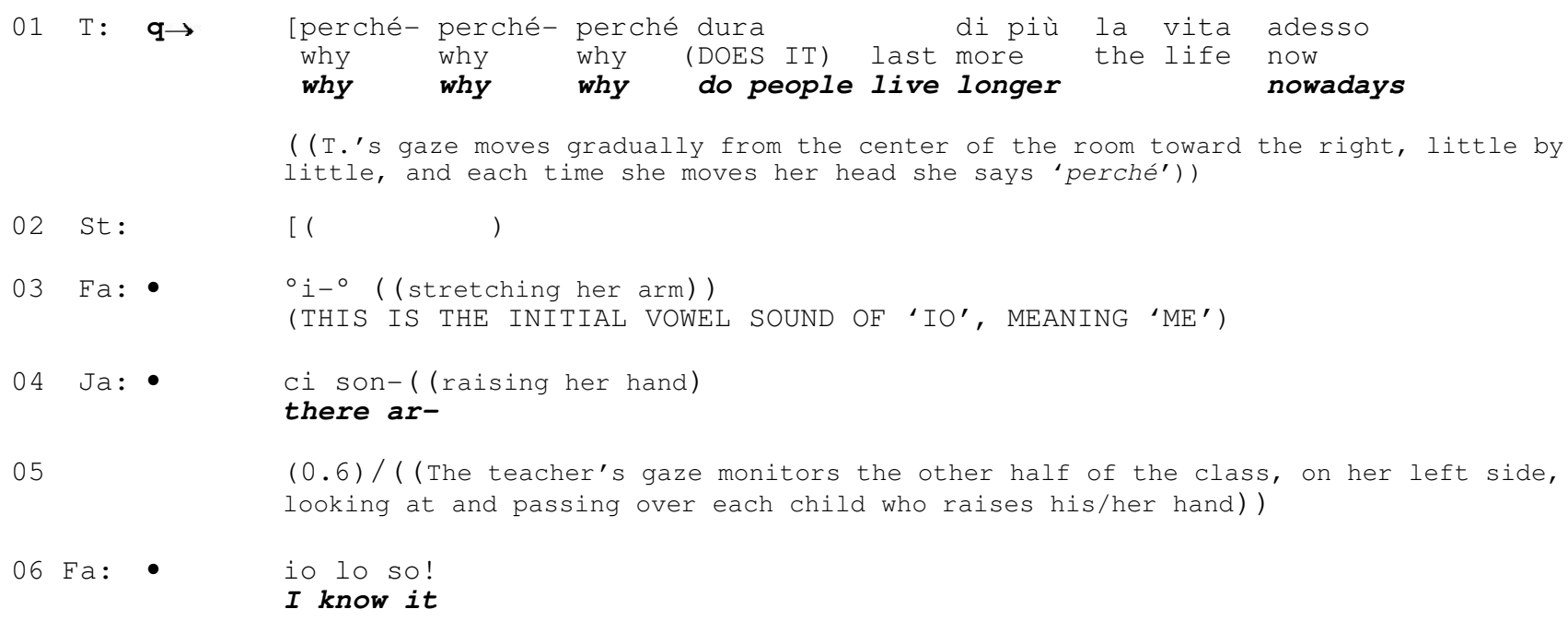




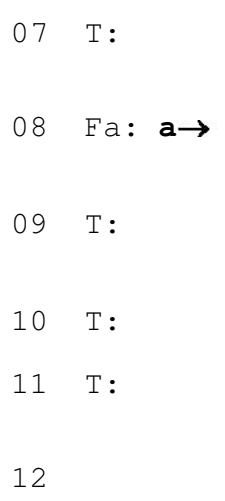

${ }_{\text {mhm }}^{\circ \text { mhm? }}{ }^{\circ}$ ((turning to Fabrizio))

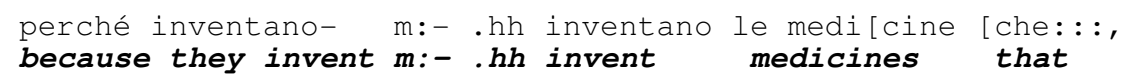

( (the teacher in the meantime gives a barely perceptible nod while looking at Fabrizio))

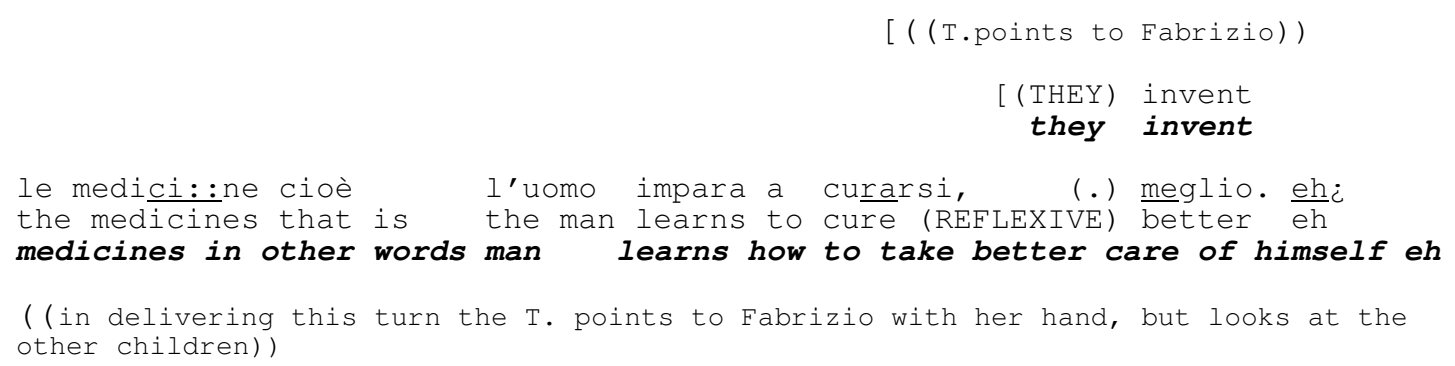

The design of the question clearly characterizes the turn as accomplishing a very different action than that of dealing with a matter-of-fact issue such as eliciting obviously known pieces of information. For starters, the questioning turn in line 1 is composed of a standing-alone interrogative, which is hearable as initiating a new question-answer sequence and which is detached from prior talk. This is grounded on a number of features.

First, the wh-word is deployed at the beginning of the interrogative. This characterizes line 1 as projecting a genuine query from the turn's very beginning; that is as a non-fortuitous question, but as one precisely designed as such. ${ }^{\mathrm{xi}}$ Second, other features in the design of the turn convey a sense of special expectation about the nature of the answer, which is cast as not being highly predictable. These include the repetition of the interrogative element ' $w h y$ ' three times ${ }^{\mathrm{xii}}$ and the fact that the teacher turns her head so as to monitor the audience in perfect synchronisation with the verbal production (see gloss to line 1). We can see that students understand the teacher's attitude towards the special status of this question type and orient to the fact that the teacher appears to assume a probable lack of knowledge of the answer by the way they organize the answering sequence: instead of a collective answer, bids for answering and the raising of hands follow the teacher's question.

A similar pattern can be identified in the following excerpt. In this segment, 'q-arrows' indicate the teacher's questions, the s-arrow the selection, and the a-arrow highlights the answer. 
(29) Angle [PM:LT:5:geometry]

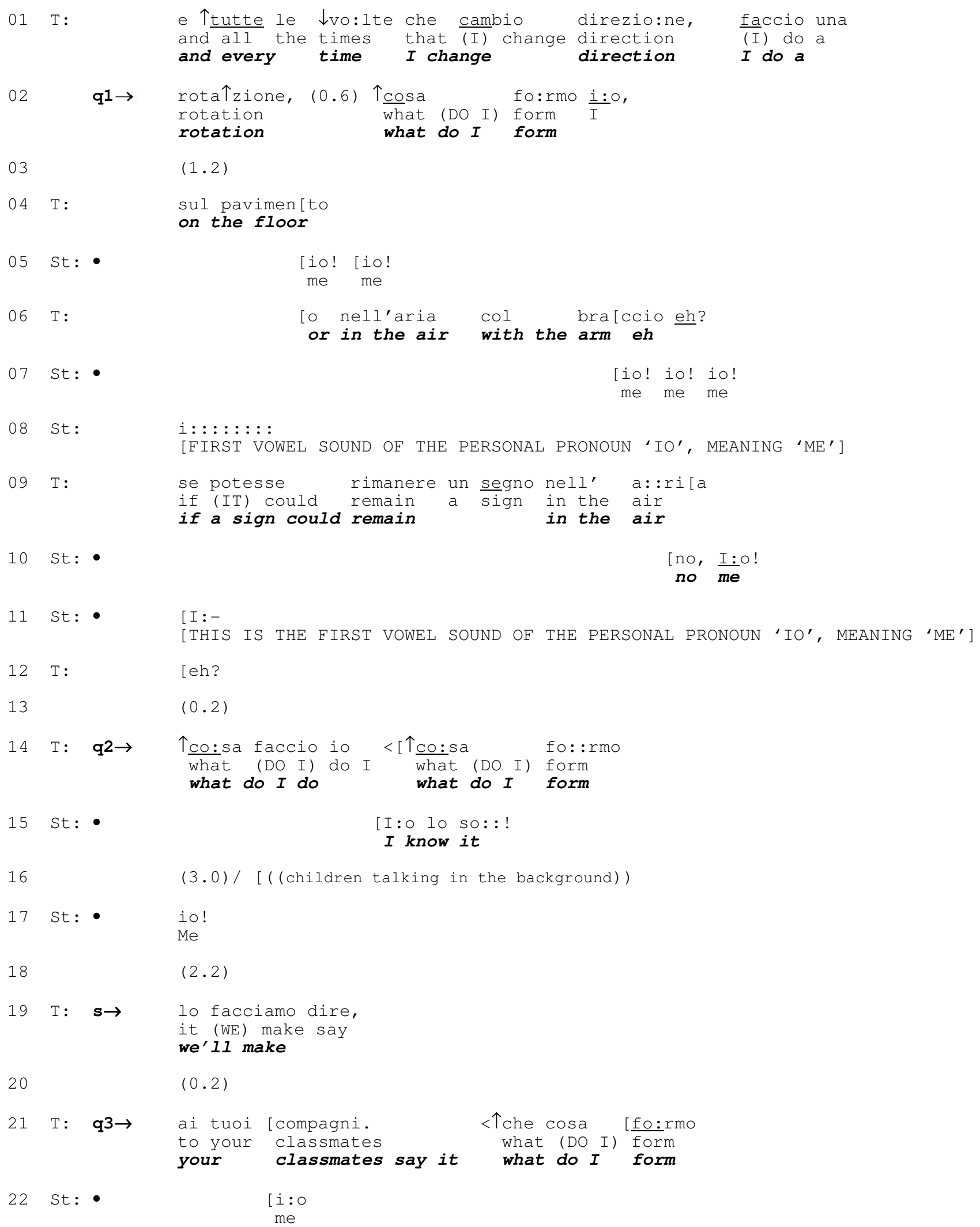




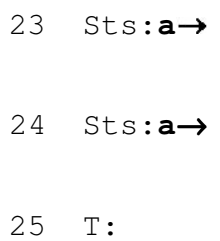

$25 \mathrm{~T}:$ [un angolo

an angle

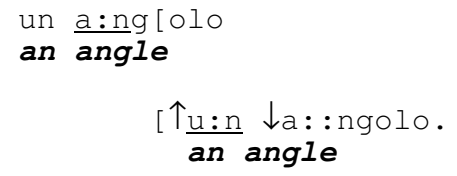

A number of features indicate that the deployment of the questions is designed to be heard as not casual. The wh-question in line 2 is, in fact, introduced by a rather extended pause which separates the wh-interrogative from the two preceding clauses and it frames the question. In addition to that, these clauses are delivered with a suspended intonation ("and each time I change direction / I do a rotation") that conveys the sense that the turn is still in progress. Both these features create expectation for the question which follows, as do the multiple increments to the first questioning turn on lines 4,6 , and 9, which are produced without any acknowledgement of the bids that students have produced in the meantime. The first increment (line 4) might be related to the students' delay in displaying any signs of knowledge of the answer, as the long pause in line 3 shows, but the other two instances (lines 6 and 9) are produced despite the students' requests to answer.

This way of delivering the question conveys that the teacher views the answer as not immediately transparent to students. By delaying the selection of the respondent and, furthermore, by taking no account of the students' requests for permission to answer, the teacher seems to draw the recipients' attention towards the substance of the question. It is interesting to note that, in the end, a choral answer is produced, but only because the teacher has overtly elicited the students to do so (lines 19-21).

Conversely, choral answers which are engendered by open questions - that is, without going through the teacher's selection, are comparatively rather less frequent. But they are normally associated with other distinct features in the construction and deployment of the questioning turn. So, it is interesting to see how teachers combine the wh-format with other features of turn construction to 
propose that there should be no doubt that the students will know how to answer correctly and properly. This sense can be conveyed by the fortuitous deployment of the question within a multi-unit turn with a declarative format. The fragment below illustrates one such pattern.

The question in 30 (line 2) is clearly occasioned by the fact that pupils are audibly speaking in overlap with the teacher's talk (line 3).

(30) Sunrise I [PM:FZ:22a:geography]

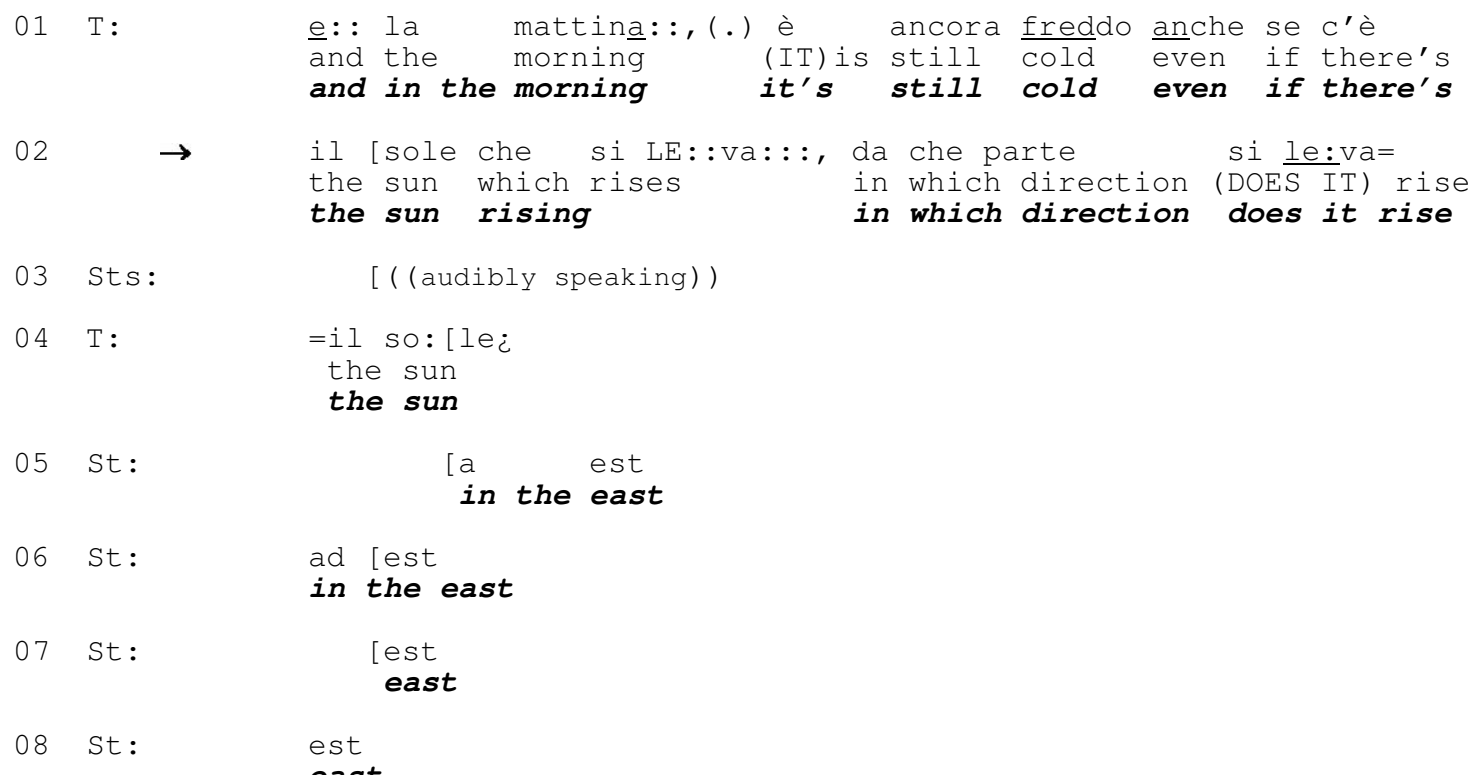

The wh-question is deployed in the course of the teacher's explanation of the reasons why the temperature is very low early in the morning. In line 2, a few bits after the disturbance has begun, the teacher distinctly raises the volume of her voice and sustains the vowel sounds to overcome the disturbance and get into the clear. This is then followed by the open question "da che parte si leva il sole? / in which direction does the sun rise ?".

Owing to the particular contingencies of the interactional moment, the question is deployed in a multi-unit turn, whose trajectory is not projectable as interrogative from the beginning. This is obviously related to the teacher's need to compete with the pupils making the disturbance. However, the placement of the question within a declarative-formatted utterance indicates that it is casually 
deployed, that it does not deserve a special treatment, and that it regards a matter that is assumed as known to students.

Following the question, in lines 5 to 8 , a number of pupils answer with individual answers. The fact that the teacher views this behavior as insufficient is demonstrated by her repetition of the same question (line 9 below) which, this time, elicits broader participation in the answer, as can be seen in the choral production (lines 10, 11, and 12):

(31) Sunrise II [continuation PM:FZ:22a:geography]

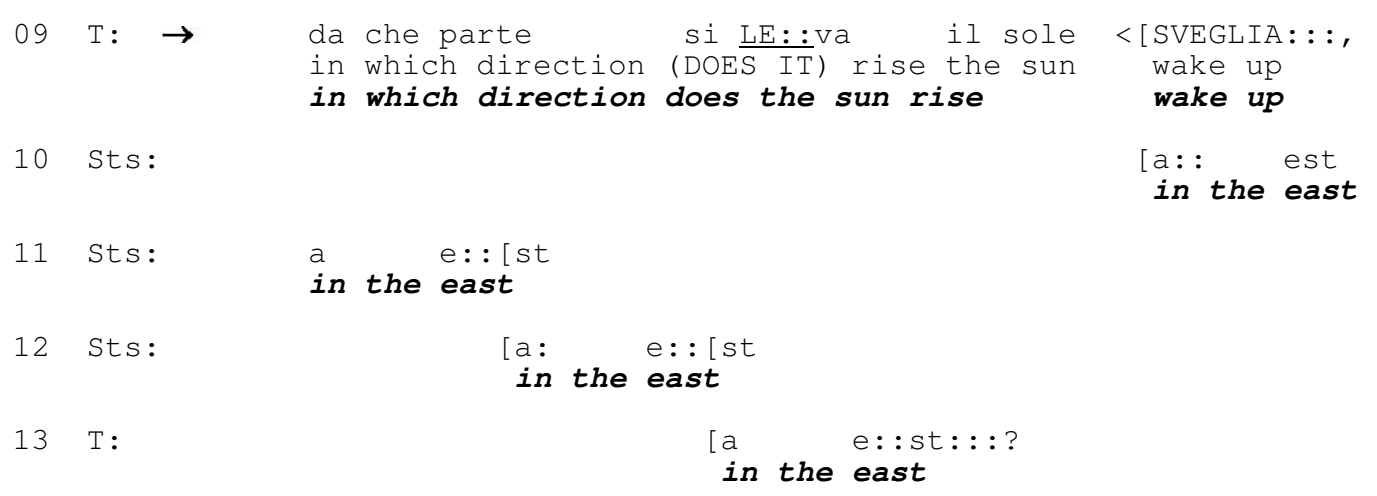

This time the students seem to recognize that the question deals with known information. Consequently, they organize themselves in groups, each one producing slightly delayed choral answers, as is the recurrent pattern for in-unison answers. By producing a verbatim repetition of the previous question - which some students have already answered - along with the call to answer ("sveglia"/ “wake up"), the teacher proposes that those who didn't respond did not hear the question. Thus, according to the teacher, the failure to answer by some in the audience is not to be accounted for the fact that they did not know the answer. The suggestion that everybody who can physically hear the question will be able to answer it adds to the sense of obviousness. Thus, it seems that the casual deployment of non-addressed open questions is interpreted by participants as being associated with a sense of the obvious. 
Fragment 32 below contains another example of the insertion of a last minute wh-question into a turn with a non-interrogative trajectory, which is thus heard as being associated with an obvious answer. The teacher is engaged in repeating the main information in a problem of division which has just been read.

(32) Boxes [PM:FZ:21:maths]

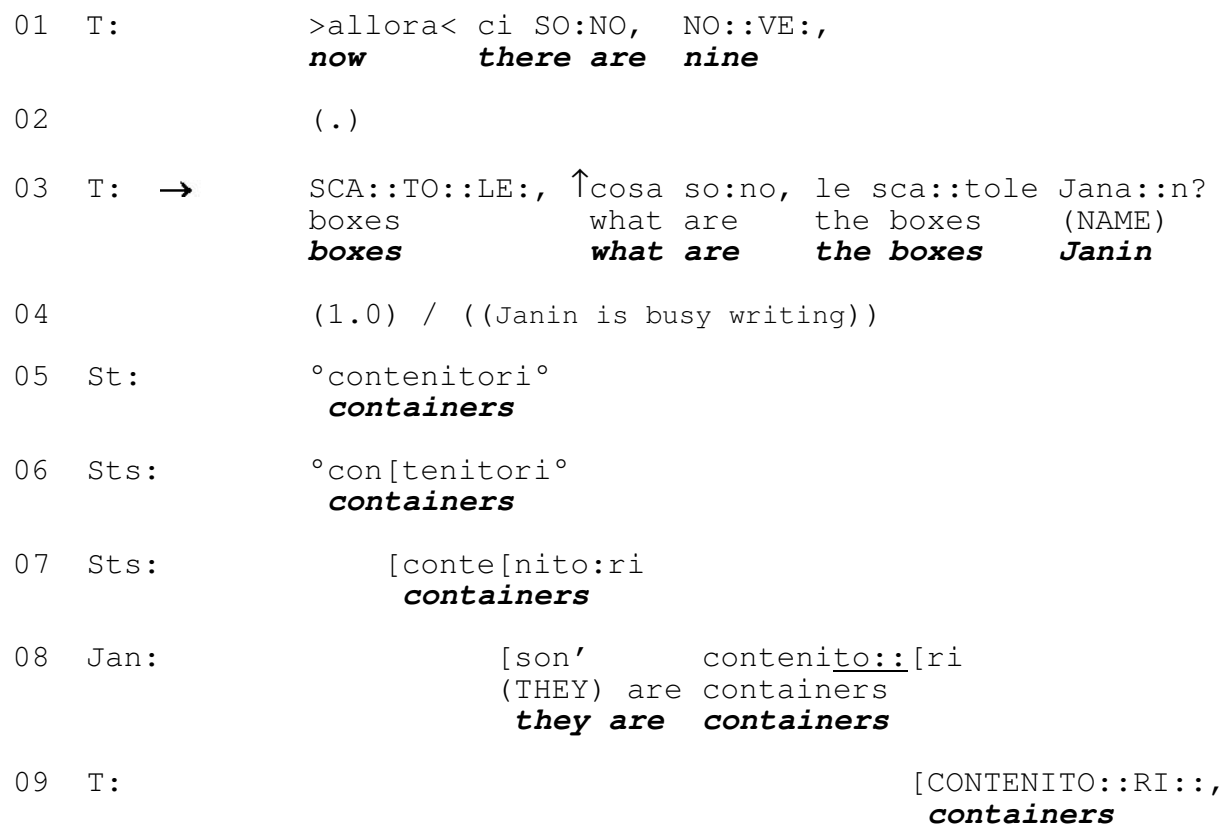

The prosodic features of the turn indicate that this is a rote activity. Note the rhythmic stretching of the vowel sound in each syllable and the suspended intonation in line 1, which resembles nursery rhyme enunciation. This repetition is also produced with a higher volume of voice than the surrounding talk. For instance, the prefatory token 'allora' is not so high, nor is the question which interrupts the repetition of the main information of the problem produced with a high volume. In the course of this rote repetition, the teacher deploys, in line 1, an instance of ECD that fails to elicit completion, or at least does not elicit it as promptly as the teacher expects. Having provided the turn continuation, the teacher then deploys the wh-question as an insertion in the ongoing activity (line 3). That the question is heard by the students as clearly eliciting an obviously known piece of information is evidenced by 
the fact that, although the question is specifically addressed to a single student, after a considerable pause (line 4) which highlights the selected student's failure to answer, the other students come in, supplying in-unison answers.

\section{Conclusions}

The investigation has focused on un-addressed question-answer sequences in classroom teacherled instructional sequences, offering a comparison between the design of questions that elicit choral answers and questions that are followed by bids to answer. I have chosen un-addressed questions as the focus of this paper because they are a favourable place for investigating how teacher and students mutually organize their activity, insofar as addressed questions can be seen as, at least partially, preallocated. Thus, the management of turn-transfer with reference to un-addressed questions offers some insights into the organization of those activities which are at the intersection of the work of constructing knowledge and that of maintaining order in the classroom.

This account does not claim to address all the methods and the practices that teacher and students use in managing the organization of question-answer sequences in the classroom setting. For instance, there might well be other question designs which operate in instructional sequences and which constrain the students' recognition of the requirements of the questions. It is important to remember that the two patterns I have described are not always or exclusively associated to the type of questioning turn reported here. For example, with reference to bids, on some occasions students may ask permission to answer even after the teacher has explicitly addressed the question to a specific student, and some students might give the answer right away while others ask permission to do so (see fragment 6). However, the distribution of these two different answering formats -choral production and bids to answer, as associated with the four types of questioning turns described here- appear to reliably 
convey to the students the teacher's stance towards the 'answerability' of the question, in terms of its transparence and obviousness in indicating the expected answer.

By showing the interactional ties that link questions to their answers, I have attempted to demonstrate that the mechanisms which make a question answerable in the classroom do not work on merely a cognitive basis. Knowing or not knowing the answer is not exclusively a state of mind which is pre-determined and which enables the students to answer (Mercer, 1995). Knowledge of the correct answer is not a cognitive state external to the interaction and independent from the way in which the interaction is organized by participants. The association between features in the construction of questioning turns and the formats of the students' answers reveal locally managed resources used by teachers to instruct the students on the expected, and thus 'correct' answer. These resources lie in the social organization of interaction.

The methods teachers use to convey their assumptions about the answerabilty of questions have important consequences for the management of the classroom social order. We must not forget that the classroom is a multi-party setting in which, as in other multi-party institutional settings, the features of talk are designed "to control or curtail the nature of audience participation in any ongoing exchange" (Drew and Heritage, 1992: 27). By designing the questioning according to precise conventions, teachers maintain the minimal conditions for the students to be able to follow the progression of talk and to provide their contribution when requested ${ }^{\mathrm{xiii}}$. It is argued that, by giving their questions different formats in relation to their answerability, teachers also convey the type of delivery which is requested for the answer (choral or individual). In this way, knowledge matters are connected to the social organization of interaction, insofar as classroom order is maintained in terms of indicating who should answer, when and in what manner, based on the students' access to the 'correct' answer. On the other hand, understanding the way in which questions are designed is important for the students, who need to be able to recognize the opportunities for them to take part in the interaction. 
Finally, I have shown that the categorization of teachers' questions exclusively on the grammatical format of the interrogative utterances does not do justice to the elements that combine to shape instructing and being instructed in a multi-party setting. First, neither the presence nor the absence of specific address terms predicts that a question will be answered by a selected student. Secondly, questioning can also be achieved through resources other than syntax. When interrogative formats are used, a number of other properties of talk play a crucial role in the construction of questioning. The variations from the basic format of syntactical patterns -such as dislocation in the order of the components as in alternative questions and other variations in the placement of the turn constructional units- as well as the production of prosodic features and the sequential deployment of questioning in the broader course of action are determining factors in the creation of a setting in which it is possible for the students to understand the requirements of the action that is thus accomplished, as these features serve to instruct them on the content of the answer and on the manner in which they should answer.

\section{References}

Atkinson, J. M., and Drew, P. (1979). Order in Court. The Organization of Verbal Interaction in Judicial Settings. London: Macmillan.

Atkinson, J. M., and Heritage, J. (Eds.). (1984). Structures of Social Actions: Studies in Conversation Analysis. Cambridge, UK: Cambridge University Press.

Cazden, C. B. (1986). Classroom discourse. In M. C. Wittrock (Ed.) Handbook of Research on Teaching (pp. 432-463). New York: Macmillan Publishing Company.

Clayman, S., and Heritage, J. (2002). The News Interview. Journalists and Public Figures on the Air. Cambridge: Cambridge University Press.

Davidson, J. (1984). Subsequent versions of invitations, offers, requests, and proposals dealing with potential or actual rejection. In J.M. Atkinson and J. Heritage (Eds.), Structures of Social Actions: Studies in Conversation Analysis (pp. 102128). Cambridge: Cambridge University Press.

Drew, P. (1981). Adults' corrections of children's mistakes: a response to Wells and Montgomery. In P. French and M. Maclure (Eds.). Adult-Child Conversation (pp. 244-267). London: Croom Helm. 
Drew, P. (1984). Speakers' reportings in invitation sequences. In J.M. Atkinson and J. Heritage (Eds.), Structures of Social Actions: Studies in Conversation Analysis (pp.129-151).

Cambridge: Cambridge University Press.

Drew, P. (1992). Contested evidence in courtroom cross-examination: the case of a trial for a rape. In P.Drew and J.Heritage (Eds.), Talk at Work: Interaction in Institutional Setting (pp.470-520). Cambridge: Cambridge University Press.

Drew, P., and Heritage, J. (1992). Analyzing talk at work: an introduction. In P.Drew and J.Heritage (Eds.), Talk at Work: Interaction in Institutional Setting (pp.3-65). Cambridge: Cambridge University Press.

Frankel, R. M. (1983). From sentence to sequence: understanding the medical encounter through microinteractional analysis. In Discourse Processes 7, 135170.

French, P., and MacLure, M. (Eds.) (1981). Adult-Child Conversation. London: Croom Helm Ltd.

Galton, M., Hargreaves, L., Comber, C., Wall, D., Pell, A. (1999). Inside the Primary Classroom 20 Years On. London: Routledge.

Garfinkel, H. (1967). Studies in Ethnomethodology, Englewood Cliffs, NJ, Prentice-Hall. Paperback Edition, 1984: Studies in Ethnomethodology, Polity Press, Cambridge.

Heath, S.B. (1983). Ways with Words: Language, Life and Work in Communities and Classrooms. Cambridge: Cambridge University Press.

Heritage, J. (1984). Garfinkel and Ethnomethodology. Cambridge: Polity Press.

Heritage, J. (1995). Conversation Analysis: Methodological Aspects. In U.M. Quathoff (Ed.). Aspects of Oral Communication. Berlin, New York: Walter de Gruyter.

Heritage, J., and Roth, A.L. (1995). Grammar and institutions: questions and questioning in the broadcast news interview. In Research on Language and Social Interaction 28 (1),1-60.

Heritage, H., and Sorjonen, M.L. (1994). Constituting and maintaining activities across sequences: And-prefacing as a feature of question design. Language in Society, 23, 1-29.

Koshik, I. (2002). Designedly Incomplete Utterances: A Pedagogical Practice for Eliciting Knowledge Displays in Error Corection Sequences. In Research on Language and Social Interaction, 35(3), 277-309.

Labov, W. (1966). The Social Stratification of English in New York City. Washington, D.C.: Center for Applied Linguistics.

Labov, W. (1984). Intensity. In Schiffrin, D. (Ed.). Meaning, Form, and Use in Context (Georgetown University Roudtable on Language and Linguistics 1984). (pp. 4370). Washington: Georgetown University Press.

Levinson, S. C., (1992). Activity types and language. In P. Drew and J. Heritage (Eds.)Talk at Work: Interaction in Institutional Settings (pp.66-100). Cambridge: Cambridge University Press.

Lerner, G. (1991). On the syntax of sentences-in-progress. In Language in Society 20 (3), 441-58.

Macbeth, D. (2004). The relevance of repair for classroom correction. In Language in Society, 33, 703-736.

McHoul, A. (1978). The organization of turns at formal talk in the classroom. In Language and Society, 7,183-213.

McHoul, A. (1990). The Organization of Repair in Classroom Talk. In Language in Society,19, 349377.

Mehan, H. (1979).Learning Lessons, Social Organization in the Classroom. MA: Harvard University Press. 
Mercer, Neil. (1995). The Guided Construction of Knowledge. Talk amongst teachers and learners. Clevedon: Multilingual Matters LTD.

Nassaji, H., and Wells, G. (2000). What's the Use of 'Triadic Dialogue'? An Investigation of Teacher-Student Interaction. In Applied Linguistics 21/3, 376406.

Nystrand, M., Wu, L.L., Gamoran, A., Zeiser, S., Long, D. (2003). Questions in Time: Investigating the Structure of Dynamics of Unfolding Classroom Discourse. In Discourse Processes, 35(2), 135-198.

Ochs, E. (1982). Talking to children in Western Samoan. Language in Society, 11(2), 77-195.

Ochs, E., and Schieffelin, B. (1983). Acquiring Conversational Competence. London: Routledge and Kegan Paul.

Philips, S. U. (1972) Participant structure and communicative competence: Warm Springs children in Community and classroom. In C. B. Cazden, V. John, and D. Hymes (Eds.), Functions of Language in the Classroom (pp. 370-394). New York: Teachers College Press.

Philips, S.U. (1983). The Invisible Culture: Communication in Classroom and Community on the Warm Springs Indian reservation. New York: Longmans. Pomerantz, A. (1988). Offering a candidate answer: an information seeking strategy. In Communication Monographs, 55, 360373. Quirk, R., Greenbaum, S., Leech, G., and Svartvik, J. (1985). A Grammar of Contemporary English. London: Longman.

Raymond, G. (2000). The structure of responding: Type-conforming and nonconforming responses to yes/no type interrogatives. Unpublished Ph.D. dissertation. Los Angeles: University of California.

Rogoff, B. (1990). Apprenticeship in Thinking. New York: Oxford University Press.

Sinclair, J., and Coulthard, M. (1975).Towards an Analysis of Discourse. The English Used by Teachers and Pupils. London: Oxford University Press.

Schegloff, E. A. (1984). On questions and ambiguities in conversation. In J.M.Atkinson and J. Heritage (Eds). Structures of Social Action. Studies in Conversation Analysis (pp.28-52). Cambridge: Cambridge University Press.

Schegloff, E. A. (1993). Reflections on Quantification in the Study of Conversation. Research on Language and Social Interaction, 26(1), 99-128.

Schegloff, E. A. (1995). Sequence Organization. Unpublished manuscript.

Schegloff, E. A., Jefferson, G., Sacks, H. (1977). The preference for self-correction in the organization of repair in conversation. In Language 53(2), 361-382.

Shultz, J. J., Florio S., and Erickson F. (1982) Where's the floor? Aspects of the cultural organization of social relationships in communication at home and in school. In P. Glimore and A. Glattorn (Eds), Children In and Out of School (pp.88-123) Language and Ethnography Series \#2, Washington, DC: Center for Applied Linguistics.

Wilkinson, L. (Ed.). (1982). Communication in the Classroom. New York and London: Academic Press.

\section{Appendix: Transcription symbols and translation}

All the examples in this study are from actual interaction recorded in the classroom while teacher and 
students were carrying out their pedagogic activities. A collection of video-recorded episodes was transcribed and analyzed using transcription notations based on the system developed by Gail Jefferson. In transcribing I tried to capture what people actually said, how they did it and when. For this purpose pauses, intonation and other features of speech delivery were considered. A fuller account of these conventions are available in Max Atkinson and John Heritage (eds.) Structures of Social Action: Studies in Conversation Analysis, Cambridge, Cambridge University Press 1984: ix-xvi. The most important symbols used here are shown below.

The relative timing of utterances

Intervals either within or between turns, or periods of silence (pauses), are shown thus (0.7) (to the nearest tenth of a second)

A discernible pause which is too short to be timed mechanically is shown as a micro-pause, thus, (.)

Overlaps between utterances are indicated by square brackets, the point of overlap onset being marked with a single left-hand bracket Contiguous utterances, where there is no discernible interval between turns, are linked by an equals sign (=). This is also used to indicate a very rapid move from one unit in a turn to the next

When part of an utterance is delivered at a pace quicker or slower than the surrounding talk it is enclosed between 'less than' $(><)$ or 'more than' $(<>)$ signs

When part of an utterance is produced in a rush it is preceded by a single 'more than' sign $(<)$ 


\section{Characteristics of speech delivery}

Various aspects of speech delivery are captured by punctuation symbols -which, therefore, are not used to mark conventional grammatical units - and other forms of notation, as follows:

A period (full stop) indicates a falling intonation

A comma indicates a continuing intonation

An inverted question mark indicates a slightly rising inflection

A question mark indicates a rising inflection (not necessarily a question) The stretching of a sound is indicated by colons, the number of which correspond to the length of the stretching

The halting in the flow of talk or the abrubt cutoff is indicated by a single dash

.h indicates inhalation, the length of which is indicated by the number of h's

h. indicates outbreath, the length of which is indicated by the number of h's

(hh) Audible aspirations are indicated in the speech in which they occur (including in laughter)

${ }^{\circ}$ o Degree signs indicate word(s) spoken very softly or quietly 
Sound stress is shown by underlining, those words or parts of a word which are emphasised being underlined

Capital letters are used to indicate a word, or part of a word, that is spoken much louder than surrounding talk

Marked pitch raises are indicated by upward arrows, thus $\uparrow$; whilst marked falls in pitch are shown by downward arrows, as $\downarrow$

If what is said is unclear or uncertain, that is placed in parentheses. So either the transcriber can hear that something is said, but cannot make out any particular sounds or words ( ); or the transcriber shows his/her 'best hearing' of what is said, (So I said)

Each line of transcription has been translated twice. The second line consists of a literal translation and often includes grammatical descriptions of items which are not directly translatable in English. These descriptions are provided in capital letters between brackets. The third line provides an attempt of an idiomatic English version.

i A similar practice has been described in Koshik (2002). According to Koshik, teachers use Designedly Incomplete Utterances (DIU) in 1-on-1, second-language writing conferences to elicit knowledge displays in error correction sequences. These are described as incomplete turn constructional units which prompts the students to complete the turn and, thus, to self-correct. The practice is very similar to what I call here Eliciting Completion Device (ECD). However, considering the different setting (multiparty) in which the practice is used, the distinctive features in terms of turn design and prosody, and the types of action it is being used to do in primary school interaction, I have decided to describe it as a different, although undoubtedly related, practice.

ii A description of the transcript conventions being used in here is available in the Appendix.

iii These results, including the calculations which are reported in Table 1 below, are from the unpublished doctoral dissertation by the same author: Piera Margutti (2004) Classroom Interaction in an Italian Primary School: Instructional Sequences in Pedagogic Settings, York: University of York (UK). 
iv In their investigation of turn transition points in news interviews, Heritage and Roth (1995) have found that, although interrogatives cover a large amount of the intreviewers' questioning turns, on a sensible number of cases questioning is accomplished through other formats which are not grammatically codable as interrogatives, but which nevertheless accomplish the pragmatic force of questioning. These are, for instance, increments, third-party attributed statements, non-attributed statements and aspects of time and speaker management. The data from classroom instructional sequences seem to yields similar results. Grammar and the interrogative formats constitute an important resource for coding questioning, but there are other utterance types that can accomplish questioning. These are, for instance, declaratives, ifformatted sentences, directives, subsentential units as appendor questions, the Eliciting Completion Device and other practices of speaker management, such as address terms to indicate that a previously formulated question is thus addressed to a specific student.

$\mathbf{v} \quad$ The example shows that the teachers' turn in line 1, although formatted as a statement, is understood by the student as projecting a question. It is worth knowing that the Italian adjective 'piccola' ('small') takes here the feminine gender, and it is thus attributed to 'città' (town) which is feminine in Italian, while 'paese' (village) is masculine. Thus, it is clear that the answer is wrong.

vi Despite a controversial relationship between quantification and the investigation of conversation, statistics has been variously used in some of the most recent CA works, as illustrated in Heritage (1995: 404-406), with relation to specific and well defined features of talk.

vii The Italian word for 'work' is composed of three syllables: 'la-vo-ro".

viii As demonstrated by Lerner (1991), speakers use a number of resources to project the compound construction of the turn underway, so as to provide recipients with an opportunity to collaboratively complete the utterance. As illustrated in the fragment below, one of such practices involves using phonological features of a prior utterance; here the number of the syllables in the spelling of the names in conversation:

(12) [CDHQ:II]

01 Mrs.R:

His name is Joe,

02 Josh:

$\mathrm{Mm} \mathrm{hm}$ ?

03 Mrs.R: $\quad$ Vandiver.

04 Josh: Vandiver?

05 Mrs.R: $\rightarrow \quad$ V-a-n,//d-

06 Josh: d-iv-e-r.

07 Mrs.R: d-i-v-e-r. Uh huh. (Lerner, 1991: 450).

Similarly, in the Temperature fragment (12), the ECD instructs the students to analyze the item into its component parts. This makes the students project the missing syllable, inviting for completion.

ix Pomerantz examines the production of questions as they are deployed in the construction of a videotaped testimony for a trial. The attorney formulates yes-no questions as part of a precise strategy geared towards instructing the suspect on the 'correct' answer. As Pomerantz explains, in order to use the videotape as evidence in the trial, it must be clear that the suspect was not coerced into making a statement. Therefore, the attorney aims at obtaining precise answers and spends the first part of the dialogue asking questions that are specifically designed to establish that the suspect has chosen to speak: "Had the attorney asked the suspect to report on how the police had treated him, for example "How have the police treated you?", the suspect would have been in a position of determining what a satisfactory answer might be. At the very least, he would have needed to determine what sort of assessment to give and whether or not to detail their treatment of him. By incorporating a Candidate Answer, "treated all right", the attorney instructed the suspect on what type of answer would satisfy their purpose: a confirmation of "treated all right" or a replacement for it" (Pomerantz, 1988: 367)

$\mathbf{x} \quad$ In his study on the interpretation of universal quantifiers as they are used by five English speakers, Labov discusses the use of quantifiers in the following examples from a 20-minute telephone call from the Ripley interview. The examples are from a telephone call the informant, Dolly Ripley, had during the interview which was part of the Lower East Side study of New York City (Labov, 1966). The call was recorded although it wasn't part of the interview because the informant was wearing a lavaliere microphone

(14a) She ain't had no kind o'nobody to bring her up.

(14b) Just to say you been around and been some place, 'cause you ain't never been no place.

(14c) I didn' bring none of my clothes back .... I left 'em all down there. That's right. I left all of'em down there. The discussion focuses on the cognitive contradiction which is involved in the use of quantifiers 
such as 'nobody', 'never', 'none', and 'all' is as follows: 'It is possible in (14a) that a child had no one to care for him or her in growing up, though it isn't likely. But it is not possible that the children being addressed in (14b) had never been any place, nor is it possible, looking at Dolly Ripley in New York City, to say that she had left all of her clothes in North Carolina" (Labov, 1984:48-49).

xi This is in contrast to the practice of deploying questioning devices within declarative-formatted turn so as to convey a sense of incidental and fortuitous question, and of obviousness, as will be shown for wh-questions which engender choral answers (fragments 30-32).

xii It can be observed that in line 2 one student is audibly speaking. Hence, we can suppose that the recycling of the turn beginning is produced so as to get into the clear and overcome the overlapping talk. However, the teacher is in the clear after the first 'perché'. The competition with the student's overlapping talk is not otherwise marked. This suggests that the other two repeated instances of the whword are produced for other reasons than competitive talk: that is, in order to mark the interrogative as embodying a special query from its very beginning.

With regards to the possible reasons why the teacher demands a choral response at this point, one might observe that numerous students have presented themselves as potential answerers. Thus, by now an in-unison answer is projectable as a concrete possibility, whereas before it was not the case.

xiii

Atkinson and Drew (1979: 220-228) propose a number of similarities between courtrooms and classrooms with regard to the ways in which talk is organized with reference to their multi-party nature. 